This item was submitted to Loughborough's Research Repository by the author.

Items in Figshare are protected by copyright, with all rights reserved, unless otherwise indicated.

\title{
Friction performance of carbon/silicon carbide ceramic composite brakes in ambient air and water spray environment
}

\section{PLEASE CITE THE PUBLISHED VERSION}

http://dx.doi.org/10.1016/j.triboint.2015.05.023

\section{PUBLISHER}

(C) Elsevier Ltd.

\section{VERSION}

AM (Accepted Manuscript)

\section{PUBLISHER STATEMENT}

This work is made available according to the conditions of the Creative Commons Attribution-NonCommercialNoDerivatives 4.0 International (CC BY-NC-ND 4.0) licence. Full details of this licence are available at: https://creativecommons.org/licenses/by-nc-nd/4.0/

\section{LICENCE}

CC BY-NC-ND 4.0

\section{REPOSITORY RECORD}

Bian, Guangyu, and Houzheng Wu. 2015. "Friction Performance of Carbon/silicon Carbide Ceramic Composite Brakes in Ambient Air and Water Spray Environment". Loughborough University. https://hdl.handle.net/2134/18281. 


\title{
Friction performance of carbon/silicon carbide ceramic composite brakes in ambient air and water spray environment
}

\author{
Guangyu Bian Houzheng Wu*
}

Department of Materials, Loughborough University, Leicestershire, UK LE11 3TU

\begin{abstract}
We have examined friction performance, friction surface structure and chemistry of a carbon/silicon carbide ceramic brake disc tested against an organic pad in air, and water spray environment. An average friction coefficient of 0.52 and 0.4 for a braking stop is achieved after bedding in air for a composite disc comprising $53.1 \%$ and $17.7 \% \mathrm{SiC} / \mathrm{Si}$, respectively. It is identified that $100 \% \mathrm{SiC} / \mathrm{Si}$ and $\sim 50 \% \mathrm{C}_{\mathrm{f}} / \mathrm{C}$ regions contribute the friction measurement. Tested in water spray, both brakes show a substantial fall of friction coefficient to a level $<0.1$. Evidences are provided for the existence of hydrodynamic friction. Friction transfer materials removal, $\mathrm{SiC}$ region polishing, and lower real contact pressure reinforce hydrodynamic process that a ceramic composite brake can experience.
\end{abstract}

Key words: carbon ceramic composite brake; friction coefficient; water; hydrodynamic friction

*Corresponding author, email: Tel.:+44 1509 223342; Fax: +44 1509 223949; E-mail Address: h.wu2@lboro.ac.uk (H.Wu) 


\section{Introduction}

Carbon fibre reinforced carbon-silicon carbide $\left(\mathrm{C}_{\mathrm{f}} / \mathrm{C}-\mathrm{SiC}\right)$, also called carbon/silicon carbide $(\mathrm{C} / \mathrm{SiC})$, ceramic composite has been progressively used as a replacement of cast iron for producing brake discs used in high performance cars since such application was successfully demonstrated more than a decade ago. ${ }^{1}$ By now, almost all commercial $\mathrm{C}_{\mathrm{f}} / \mathrm{C}$-SiC brake discs are paired with pads that are made of so-called low metallic friction material (also called organic pads), a type of composite that all abrasives, lubricants, fillers and reinforcements are bonded by resin. Metallic ingredients are included to improve the wear resistance, thermal diffusivity and mechanical robustness ${ }^{2}$. Organic pads themselves are widely used to pair with a cast iron brake disc for a brake in a road vehicle. As known already, friction performance of a brake is highly sensible to the composition of such type of friction material ${ }^{3,4,5,6,7}$. However, there is not yet sufficient tribological knowledge published about a friction pair that consists of $\mathrm{C}_{\mathrm{f}} / \mathrm{C}$-SiC and low metallic friction material, whilst one may expect that extensive testing must have been done in industry to achieve/optimise the required friction performance of a carbon ceramic brake, as noted by Krenkel in the early time ${ }^{8}$.

In the past years, a number of papers have been published on the tribological performance of carbon ceramic composite tested against itself under specific testing conditions, aiming for self-mated friction application. In general, cracking damage induced by abrasion in the contact regions, and oxidation caused by friction heat are the essential tribological mechanisms that govern the friction performance of a brake and its variation with testing conditions. ${ }^{9,10,11}$ However, such knowledge can hardly be transferred and applied to a carbon 
ceramic disc paired with an organic pad, because the structure and chemistry of the friction contact regions are changed, leading to different chemical and mechanical processes involved in braking.

$\mathrm{C}_{\mathrm{f}} / \mathrm{C}$-SiC composite brake disc was recently tested and studied against organic pads ${ }^{12,13,14}$, and sintered metallic materials ${ }^{15}$, on a testing car, full-scale dynamometer, or laboratory-scale dynamometer. The studies have demonstrated that testing results generated from laboratory-scale dynamometer can provide sufficient understanding for predicting what could happen for a brake tested on a testing car, or a full-scale dynamometer ${ }^{12,13}$. It was found that, among all tests, there exists a clear bedding stage that significant numbers of braking stop are needed for a brake to achieve a stable friction coefficient. Examination of friction surface has revealed that in general friction transfer layer is not easily deposited on the friction surface of a carbon ceramic disc with a strong bond ${ }^{16}$. Based on such prior knowledge, we are further motivated to know how the variation of ceramic constituents in $\mathrm{C}_{\mathrm{f}} / \mathrm{C}$-SiC composites would influence the friction coefficient at bedded stage, and the bedding process as well.

For a traditional cast iron brake disc, when it is tested against typical organic or sintered pads, a friction transfer layer, typically composed of a dense mixture of iron oxides and compounds such as lubricants, fillers and abrasives that originated from pads ${ }^{4,17}$, is fairly easily developed with a strong bond through fusing with iron matrix. Therefore, the focus of a cast iron brake has always been on the friction layer development on the contact surface of a pad, because it is the friction surface of a pad that largely dictates the bedding time required for a cast iron brake, as well as the level of friction coefficient after bedding. For a carbon ceramic brake, 
however, this is not the case, as demonstrated already ${ }^{14,18}$, and brake disc could take longer time than pad to complete the bedding. Therefore, attention on friction surface of the disc is necessary.

On the other hand, the weak bond of a friction transfer layer on surface of a carbon ceramic disc likely makes the layer very susceptible to solvents ${ }^{16}$, like water, when they are involved in friction contact regions. When friction transfer layer becomes a key factor in defining the friction performance of a brake, the loss of a friction transfer layer might bring significant change of friction coefficient of a carbon ceramic composite brake. By now, all studies on carbon ceramic composite brakes are conducted in ambient air atmosphere, their friction behaviour in wet is remained as unknown at least in literature, if not in industry. We will therefore examine its friction behaviour when a carbon ceramics brake is tested in a wet environment.

However, friction performance in solvent for a cast iron brake does not seem to be a main concern. For the mostly used testing standard, SAE J $2522^{19}$, testing in wet environment is not even included in the suggested testing programme. However, recent studies ${ }^{20,21}$ demonstrated that friction coefficient of a cast iron brake could fall in wet environment, and the fall was enhanced by the increase of sliding speed or the reduction of braking pressure. The underpinned mechanism for the fall was believed to be associated to (a) the loss of friction transfer layer from friction surfaces of disc and pads; (b) the formation of water film that can reinforce the hydrodynamic process of contact surfaces; (c) the cooling of the friction surfaces 
that might reduce friction contact region. Therefore, it is interesting to know how the friction coefficient of a carbon ceramic composite brake is governed when it is operated in a wet environment.

\section{Experimental procedures}

\subsection{Materials for brakes}

Two commercial $\mathrm{C}_{\mathrm{f}} / \mathrm{C}$-SiC composites were chosen to be brake discs on the basis that they provide significantly different content of $\mathrm{SiC} / \mathrm{Si}$ and carbon fibre/carbon $\left(\mathrm{C}_{\mathrm{f}} / \mathrm{C}\right)$ constituents. Information on their microstructure was analysed, and is reported in Results and discussion section. For a brake including a composite disc with a high fraction of $\mathrm{SiC} / \mathrm{Si}$, we hereafter called Brake-H, and the one with a low fraction called Brake-L. Grade BS EN 1561 grey cast iron was chosen to be manufactured into a brake disc, and then tested under same conditions as for the composite discs.

A commercial brake pad (Pagid PV30 V3, TMD Friction, Inc.) was selected, and machined into a pad fitting to the testing set up. Same pad was tested against all ceramic composite and cast iron discs. Due to commercial reasons, it is unlikely to know the details of chemicals in this pad. However, its main chemical elements and microstructure were analyzed, and are reported in Results and discussion section.

\subsection{Brake disc and pad manufacture}


All testing discs have a diameter of $60 \mathrm{~mm}$ and thickness of $15 \mathrm{~mm}$, and were directly cored from the as-supplied material blocks by using core drill, followed by grinding to achieve the flatness and parallel requirements on friction surface. All testing surfaces were polished using a KEMET lapping machine (Kent, UK). Polishing was carried out using three grades of diamond slurry: 68,8 and $3 \mu \mathrm{m}$, started from the coarse one and finished with the finest. The fine surface finish was adapted to minimise the difference of surface topography among the as-finished friction surface, which might influence the friction measurement. The drawing of the disc is shown in Figure 1 (a).

The as-acquired pads were first cut into a ring shape with outer diameter (OD) of $50 \mathrm{~mm}$, inner diameter (ID) of $38 \mathrm{~mm}$ and height of $4 \mathrm{~mm}$, followed by further machining to remove material off from the ring to achieve two symmetrically positioned arc segments; each segment corresponds to a quarter of the total length of the ring. The drawing of the pad is shown in Figure 1 (b). The surface of the as-machined pad was finished by 500 grade SiC sand paper before being used for test.

\subsection{Braking test}

The friction testing was conducted on a laboratory-scale dynamometer with inertia of 4.70 $\mathrm{gm}^{2}$. Details on this testing rig are available in reference 14 . The testing procedure used in this study is summarised here. For each braking stop execution, a disc was firstly accelerated to a rotation speed of around $10,000 \mathrm{rpm} \pm 10 \%$ by compressed air, equivalent to a sliding speed of $20 \mathrm{~m} / \mathrm{s}$ at the circular position having an effective radius of the friction contact track. Such a 
sliding speed is close to the motorway braking speed of a front brake designed for high end automotive vehicles. ${ }^{22}$ Then, a pad was pushed onto the disc with a constant brake pressure of 3.6 MPa to decelerate the spinning of the disc until it was completely stopped. Note, braking pressure for a typical automotive vehicle is $>1.2 \mathrm{MPa}$, and could be close to $10 \mathrm{MPa}$ in extreme situations, ${ }^{23}$ and the chosen pressure is inside this region. Same execution was repeated according to the requirements of each testing programme. For consecutive braking stop, the interval between executions was maintained the same as 5 seconds.

For each braking stop, the rotation speed, braking load, and braking torque were collected by a data logger with a capture frequency of $50 \mathrm{~Hz}$. Friction coefficient was calculated using the following equation:

$$
\mu=\frac{T}{P_{0} \times S_{e} \times R_{e}}
$$

where $T$ is braking torque, $P_{0}$ braking pressure, $S_{e}$ is the friction contact area $\left(S_{e}=\frac{1}{8} \times \pi \times\right.$ $\left.\left(50^{2}-38^{2}\right)=414.48 \mathrm{~mm}^{2}\right), \quad$ and $R e$ effective radius $(22 \mathrm{~mm}$ here $)$ of the friction contact track.

When a tested brake was bedded, water spray was applied to carry on the braking test. A water spray device was installed right above engaging position between disc and pad, as illustrated in Figure 2. Water was supplied from a tap by pushing through a shower head onto braking contact interface. Before wet test started, the bedded brake was showered for $1 \mathrm{~min}$ to have friction surfaces soaked with enough water. During testing, a constant flowing rate, $\sim 1$ 
litre/min, of water had been sprayed until the test programme was finished.

The braking test programme adapted in this study was started with an as-finished disc and pad on testing rig in ambient air environment, to have a brake fully bedded by completing bedding. A total of 200 braking stops were applied in a consecutive way. Then, braking test in water spray environment was followed with 20 braking stops applied in a consecutive way. In order to examine friction surface in-between braking executions, a separate test programme was conducted; at an interested point the tested disc was taken off from the rig for necessary characterisation, before it was reinstalled on the rig to carry on the prescribed test.

\subsection{Surface characterization}

The microstructure of a friction surface was examined by using optical microscopy (OM) on a MeF3 microscope (Reichert-Jung, Wien, Austria) under a polarized and differential interference contrast (DIC) lighting condition, and scanning electron microscopy (SEM) on Leo 1530vp FEG-SEM (Zeiss, Germany) under an accelerating voltage of $10 \mathrm{kV}$. Energy Dispersive X-ray Spectroscopy (EDXS) (X-Max, FEI, USA) was used to examine the chemical composition.

Surface roughness, an arithmetic average of absolute values ( $\mathrm{Ra})$, was measured along the tangential direction of a braking contact track with a surface profilometer (Mitutoyo SJ210, UK) by using a tip of $1 \mu \mathrm{m}$ in radius. The moving speed of the tip was $0.5 \mathrm{~mm} / \mathrm{s}$ and the scanning distance was $4 \mathrm{~mm}$ with a cut off, or sampling length, of $0.5 \mathrm{~mm}$. 


\section{Results and Discussion}

\subsection{Microstructure and chemicals on as-finished surface of brake disc and pad}

Representative OM images of as-polished surface of the two ceramic composite discs studied in this paper are shown in Figure 3. $\mathrm{C}_{\mathrm{f}} / \mathrm{C}, \mathrm{SiC}$ and $\mathrm{Si}$ regions are clearly differentiated under a polarised and DIC lighting condition, and are labelled in each image. The composite disc used in Brake-H has a significantly high $\mathrm{SiC}$ and $\mathrm{Si}$ content than that in Brake-L. Carbon fibres in Brake-H are short ones, and those in Brake-L were long ones. It is noted that both ceramic composites are highly heterogeneous in terms of the size of $\mathrm{SiC} / \mathrm{Si}$ and $\mathrm{Cf} / \mathrm{C}$ regions, and their distribution on the surface. For a ceramic composite manufactured via silicon-melt infiltration, $\mathrm{Si}$ in $\mathrm{SiC} / \mathrm{Si}$ regions is always surrounded by $\mathrm{SiC}$ that is developed through the reaction between silicon melt and carbon $^{24}$; and carbon fibres in $\mathrm{C}_{\mathrm{f}} / \mathrm{C}$ regions are away wrapped by pyrolytic carbon (C) that could be derived from carbonaceous resins ${ }^{25}$, or gases ${ }^{26}$, depending on which manufacture route is used. Microstructure for this type of composite is detailed in literature ${ }^{27,28}$, and is out of the interest of this paper.

However, the relative content of the constituents may relate to friction performance of a brake.

By using image software, Image-J software (NIH, USA), the area fractions of SiC, Si and $\mathrm{C}_{\mathrm{f}} / \mathrm{C}$ regions are estimated and summarised in Table 1 . It is apparent that the fraction of $\mathrm{SiC} / \mathrm{Si}$ regions on the brake disc surface of Brake- $\mathrm{H}$ is over 3 times of that of Brake-L. Therefore, it is interesting to know how the difference had influenced the brake's friction 
performance.

Friction performance of a brake is tightly associated to the pad as well. A representative OM image of as-polished surface of a pad is shown in Figure 4. The main constituents, such as steel and copper are distinguished easily and labelled in the image. Other constituents as fillers, abrasives, lubricants and binders cannot be recognized clearly in an OM image. However, the typical chemical elements were detected with EDXS, and the results are summarized in Table 2. It should be noted that, due to the highly heterogeneous nature of a friction material, the quantitative value for each element is informative only, which can become the key sources of chemical footprints on a friction surface. As noted, a significant amount of $\mathrm{Fe}, \mathrm{Cu}, \mathrm{C}$ and $\mathrm{O}$ exist inside the pad.

\subsection{Friction in ambient air}

The averaged friction coefficient measurement for each braking stop is presented in Figure 5, including test in ambient air and water spray environment. The variation of friction coefficient will be examined, along with the friction surface topography and microstructure.

\section{(i)Friction coefficient in ambient air}

As shown in Figure 5, the measurement for both $\mathrm{C}_{\mathrm{f}} / \mathrm{C}$-SiC composite brakes rose from a level of low to high by approximately following a parabolic shape, as braking stop number increased. This characteristic trend at bedding stage was demonstrated in a previous study ${ }^{14}$. For Brake-H, the friction coefficient measurement started with a level of $\sim 0.3$, followed by a 
steady ascending to a level around 0.47 after $\sim 100$ braking stops. Subsequently, further braking execution had little change of friction coefficient measurement, and a level of $\sim 0.47$ was maintained till after 180 executions. From the $181^{\text {st }}$ to $200^{\text {th }}$, the measurement showed a further, but small rise to another fairly stable level of $\sim 0.51$. For Brake-L, a similar ascending trend was observed from the start to the $85^{\text {th }}$ execution, and a stable friction coefficient of $\sim 0.4$ was since maintained till the end of test in ambient air.

Based on the observation above, we can phenomenologically describe the variation of averaged friction coefficient, $\bar{\mu}$, versus the braking stop number, $n$, by using a standard parabolic equation:

$$
\bar{\mu}=a n^{2}+b n+c
$$

where $a, b$ and $c$ are parameters. To quantitatively compare the friction performance of the two composite brakes at the bedding stage, measurements at this stage are fitted to eq. (2), and parameters $a, b$ and $c$ for each brake are summarised in Table 3 . The coordinate of the vertex of a parabola is $(167,0.5)$ and $(115,0.42)$ for Brake-H and Brake-L, respectively. The following points can therefore be drawn:

(a) The $\bar{\mu}$ at vertex represents the friction coefficient level at stable friction. Brake-H gave 19\% higher friction coefficient than Brake-L. The predicted CoF ratio between Brake-H and Brake- $\mathrm{L}$ is 1.19 , which is just inside the ratios of true asymptote shown in Figure 4: 1.18 and 1.28 for the first stable friction coefficient of 0.47 and the second one of 0.51 , respectively, for 
Brake-H.

(b) Brake-H took $45 \%$ more braking stops than brake-L to achieve a stable friction.

It is interesting to see that, when tested against same organic pad materials under same braking conditions, the composite disc that consisted of more than 2 times higher $\mathrm{SiC} / \mathrm{Si}$ took more braking executions to achieve a stable friction, and likewise provided slightly higher level of friction coefficient. Friction force for a friction couple should include the adhesion forces existing on all friction contact regions if the friction is dictated by an adhesion mechanism ${ }^{29}$, and the ploughing resistance if a ploughing process is included. When the friction surfaces are flattened by polishing before test, it should be a reasonable assumption that friction of this friction couple is predominantly dictated by adhesion, and the CoF can therefore be expressed as following equation:

$$
\bar{\mu}(n)=\frac{\lambda \sum_{1}^{m} s_{i}}{s}=\lambda f(n)
$$

where $\lambda$ is adhesion force per area of each friction contact region, $s_{i}$ area of each contact region, $S$ nominal area of friction contact interface, and $f$ fraction of total contact regions out of the friction contact interface. $\lambda$ ought to be a constant for a given braking condition, $f$ should be a function of braking stop number $n$ at bedding stage, because the number of contact region, $m$, and the area of each contact region, $s_{i}$, tend to increase as bedding proceeds. At bedded stage, the friction contact regions become stable, leading to a constant friction coefficient. According to this analysis and the observed ratio of friction coefficient between the two brakes, Brake-H 
ought to have higher fraction of friction contact region than Brake-L, and the results of friction surface examination are shown below.

\section{(ii) Friction surface after bedding and friction contact area}

Representative OM and SEM images of the friction surfaces of the composite discs, subjected to 200 braking stops in air, are shown in Figure 6. On both surfaces, transferred materials were clearly deposited in $\mathrm{SiC}+\mathrm{Si}$ regions either as a continuous layer on top of the regions, as shown in Figure 6(a), or as fillers in crevices or craters that were likely formed through surface fracture during braking, as shown in Figure 6(b). It seems that the whole $\mathrm{SiC} / \mathrm{Si}$ regions were in full friction contact during braking, based on this observation. In the $\mathrm{C}_{\mathrm{f}} / \mathrm{C}$ regions, transferred materials were deposited in a patched manner. Some became part of load bearing regions, along with carbon materials - particularly most of the exposed carbon fibres, but some were fairly powdery, which unlikely bore any load, or in contact with pad surface.

The observation shows that the change of $\mathrm{SiC}+\mathrm{Si}$ content in the composites has little influence on the deposition of transferred materials on friction surfaces. The load bearing regions, or the contacted areas, included all $\mathrm{SiC}+\mathrm{Si}$ regions, and part of the $\mathrm{C}_{\mathrm{f}} / \mathrm{C}$ regions. Most of these load-bearing contact regions on a fully bedded surface show white grey or dark grey contrast under OM imaging conditions. By using Image-J, the fraction of friction contact area on a brake disc is estimated as $76.8 \pm 8.3 \%$ and $57.2 \pm 10.5 \%$ for Brake- $\mathrm{H}$ and Brake- $\mathrm{L}$, respectively. The estimation gives a load bearing area ratio, $f^{H} / f^{L}$, of 1.34 for the disc in Brake-H to that in Brake-L, just slightly larger than the upper bound of ratio of friction 
coefficient $\left(\bar{\mu}^{H} / \bar{\mu}^{L}\right)$, indicating the averaged friction coefficient of a braking stop is proportional to the fraction of friction contact regions, as predicted by eq.(3).

On the other hand, it is necessary to examine the friction surface of the pads. Representative OM and SEM images of friction surface of the organic pad, subjected to 200 braking stops by testing against the $\mathrm{C}_{\mathrm{f}} / \mathrm{C}-\mathrm{SiC}$ composite disc in Brake-H, are presented in Figure 7. Three types of regions can be distinguished based on the contrast of the secondary electron image: white grey, dark grey and black, associated to copper and/or iron, silicon and oxygen, and carbon, respectively. The friction surface had been fully bedded, except $\sim 20 \%$ voids remained, as estimated from OM images by using Image-J. It is clear that the friction contact area on a pad surface was larger than that on a composite brake disc. Therefore, it should be a reasonable assumption that friction coefficient at bedded stage was dictated by the friction contact area on a composite disc.

As evidenced, all $\mathrm{SiC} / \mathrm{Si}$ regions seem to be in friction contact during braking, it is therefore possible to estimate the fraction of friction contact area in $\mathrm{Cf} / \mathrm{C}$ regions at bedded stage by following eq. (3). With the measurements shown in Table 1 and the measured fraction, $76.8 \pm 8.3 \%$ and $57.2 \pm 10.5 \%$, of all friction contact regions on a brake disc in Brake-H and Brake-L respectively, we have estimated that $50.6 \%$ and $48.0 \%$ of $\mathrm{C}_{\mathrm{f}} / \mathrm{C}$ regions was in friction contact in Brake-H and Brake-L, respectively. The fairly close estimation implies that bedding had similar impact on all $\mathrm{C}_{\mathrm{f}} / \mathrm{C}$ regions in developing load bearing regions by either depositing transferred 
materials or abrasion. The fact that nearly half of surface of $\mathrm{C}_{\mathrm{f}} / \mathrm{C}$ regions might have contributed the friction contact during braking should be the main reason that $\mathrm{SiC} / \mathrm{Si}$ content in a composite brake disc had a disproportionately impact on measurement of averaged friction coefficient of a braking stop.

It is not possible yet here to provide direct evidence why the Brake-H needed more braking stops for the bedding, owing to no systematic examination was done on the friction surfaces at bedding stage. The possible reasons can be speculated only: (a) different bedding speed of friction surface of a pad when it was tested against different brake disk; (b) different bedding speed in $\mathrm{SiC} / \mathrm{Si}$ regions, probably owing to the significantly larger real contact pressure applied on $\mathrm{SiC} / \mathrm{Si}$ regions in Brake-L, comparing to Brake-H, which could promote the bedding on both friction surfaces of brake disc and pad. Nonetheless, further experimental investigation is needed in order to have better understanding and sound conclusions.

\subsection{Friction performance in water spray environment}

\section{(i) Friction coefficient}

The averaged friction coefficient for each braking stop is presented in Figure 8 for the segment tested in water spray environment only. When water spray was applied, the friction coefficient dropped instantly to a level less than 0.2 , more than $50 \%$ fall from a level at bedded stage. As the test continued with more braking stops added, the fall carried on, but in a decelerated trend.

The diagram shown in Figure 8 can be visually divided into two regimes. For Brake-H, region-I 
corresponds to the first 8 braking stops, indicating a clear fall trend of friction coefficient from 0.165 to 0.05 , followed by a fairly stable friction at a level around 0.05 , called region-II. For Brake-L, the region-I extended to a braking number of 14 , showing a fall of friction coefficient from 0.19 to 0.095 before reaching to region-II. Both regimes are labelled in Figure 8.

Between the two brakes, there is little difference in variation pattern of friction coefficient with braking stop number, but friction coefficient for brake-H was always $0.05-0.07$ smaller than that for Brake-L. For both brakes, the stable friction coefficient under wet testing conditions, 0.05 for Brake-H and 0.095 for Brake- $\mathrm{L}$, is well below an expected level for a brake that is suitable for road vehicles. Following the adhesion model shown in eq.(2), one would expect that the friction contact area in Brake-H would be smaller than that in Brake-L, which will be examined and analysed below for the truth.

To eliminate any other factors that could cause such poor wet friction performance, we tested a cast iron brake disc against the same pad under same testing conditions. The friction coefficients are plotted in Figure 9 from bedding to bedded stage in air, followed by water spray. The brake was bedded quickly in ambient air. When water spray was applied, a stable friction was maintained in a same level as that after bedding. In fact, there was a fast increase of friction coefficient from 0.4 to 0.5 for braking stops after water spray was applied; a further increase to a level around 0.55 to 0.67 was observed as braking continued under such conditions. One may attribute (a) the high friction coefficient to the higher braking pressure used in this study, and (b) a reinforced ploughing friction mechanism that was demonstrated by clear ploughing grooves 
left on friction surface of cast iron. The earlier one might not have significant impact as the braking pressure is still inside the regime of braking pressure used by brakes of normal automotive vehicles. However, the later one could have more dominant impact as organic pad used for carbon ceramic brake disc is expected to be harder, which can plough the hardened surface of cast iron in a cold environment. Nonetheless, further understanding of cast iron brake's friction is out of the range of this paper, and a quantitative study is needed.

The comparative study does suggest that neither testing conditions nor pad itself had any critical contribution to the poor wet friction performance of a ceramic composite brake. The problem ought to be ceramic composite disc itself, and non-boundary friction was hence reinforced due to the existence of water. Therefore, the following analysis will focus on the composite disc, including tomography and microstructure of its friction surface, as well as necessary conditions for non-boundary friction during braking.

\section{(ii) Impact of sliding speed on friction performance in water spray environment}

If water spray during braking brings the non-boundary friction, i.e. hydrostatic friction, into the process, i.e. water acts as a lubricant between contact surfaces of a brake, sliding speed of the friction pair should have a significant impact on the coefficient friction, which can be demonstrated by plotting the friction coefficient against the velocity $(v)$, or a parameter including velocity, viscosity of lubricant $(\eta)$, and contact pressure $(p)$. This type of plot is widely called Stribeck plot $^{30}$. 
For each braking stop, the sliding speed started from the highest and ended at the lowest. Having $\eta=8.9 \times 10^{-4} \mathrm{~Pa}_{.}{ }^{31}$ for water and $p$ as the nominal pressure of braking, we can plot the instantly logged friction coefficient inside a braking stop against $\log (V \eta / p)$. Representative plots are shown in Figure 10 (a) and (b) for Brake-H and Brake-L, respectively.

From the shape of the curves, the following points can be drawn:

(a) Around the low sliding speed end with smaller values of $\log (V \eta / p)$, which was near the end of each braking stop, there was no a plateau showing that friction coefficient was insensitive to sliding speed. This fact implies that there was no full boundary friction (also called boundary lubrication), during braking for all braking stops of both brakes.

(b) Around the higher sliding speed end with larger values of $\log (V \eta / p)$, which was around the start of each braking stop, most curves had not reached a flattened stage, apart from a large fluctuation among the data, which is deemed due to vibration of testing rig at high rotation speed. However, as the braking number increased to 20, there was a tendency to become flattened, and this tendency became more obvious for Brake-H. Such flattening, or even slightly ascending trend, implies that hydrodynamic friction (also called hydrodynamic lubrication) tended to become in dominant at the initial stage of braking when enough braking stops were applied in water spray environment.

(c) In between the low and high speed regime, all braking stops showed a continuous fall 
of friction coefficient as the sliding speed, or $\log (V \eta / p)$, increased. Such trend indicates without ambiguity that the friction in this region was governed by a mixed mechanism of boundary and hydrodynamic friction, and the friction surfaces had a partial contact only. As the braking proceeded, contribution by hydrodynamic friction reduced continuously, and boundary friction increased at the same time, owing to the reduction of sliding speed.

Based on the above analysis, it is apparent that water spray immediately changes full boundary friction operated in ambient air into partial boundary one, and the appearance of hydrodynamic friction brings the friction coefficient down significantly. To understand the variation of averaged friction coefficient with the number of braking stop and the difference between Brake-H and Brake-L, we need to examine the friction surface further.

\section{(iii) Topography of friction surface}

The measurements of surface roughness, arithmetic average roughness $(\mathrm{Ra})$, of a friction surface after testing in wet environment are presented in Figure 11 for both disc and pad of a brake. For Brake-H, the Ra of the disc friction surface increased from 1.8 to $2.1 \mu \mathrm{m}$ when the test in wet was started. As the test proceeded, there was little change, whilst the standard deviation increased from the first to the last braking stop. The Ra for the pad had virtually no change, maintaining a level of 4.1-4.3 $\mu \mathrm{m}$. For Brake-L, it seems the Ra of the brake disc had a little reduction from $\sim 1.0 \mu \mathrm{m}$ to a level between $0.8 \mu \mathrm{m}$ and $0.9 \mu \mathrm{m}$ after wet tests. The Ra of the friction surface of pad reduced from 3.5 to $2.8 \mu \mathrm{m}$ when the water spray was applied, 
but increased to $3.5 \mu \mathrm{m}$ at the end of wet test.

It is noted that the measurements of Ra had a large variation, accompanied by a large standard deviation. This might be due to a fact that the composites for both brake disc and pad are highly heterogeneous at a macro-scale level, which is comparable to the sampled range by the stylus. It is therefore highly likely that one measurement was heavily weighted by one particular feature on the surface. For instance, the voids and friction plateaus can contribute differently from one measurement to another. Having this accounted, and based on the measurement of the Ra, we don't believe that water spray had any radical change of the surface tomography in such large scale, i.e. the friction plateaus developed through bedding in ambient air were approximately maintained in the same format. The only exception is that the Ra for composite $\mathrm{H}$ had small increase after the wet tests probably due to the removal of transfer materials, particularly these deposited in $\mathrm{C} / \mathrm{C}_{\mathrm{f}}$ regions. If the hydrodynamic lubrication had associated with roughness of friction surface at such a scale, the variation of friction coefficient with the sliding speed would not have varied, or even showed an increasing trend, from one braking stop to another one. Assume each braking cycle removes a certain amount of friction transfer layer off from the friction surface, and the consequence of this a cyclical dynamic braking process would make the friction surface rougher, leading to more boundary friction and therefore increased friction coefficient.

Under such circumstance, the fall of friction coefficient with braking stop in water spray must be associated to the change of friction contact regions, rather than the macro-scale 
topographic structure of friction surface. For the composite disc, these plateaus were identified in section 3.2, and are examined further after braking in water spray environment.

\section{(iv) Friction plateaus in water spray environment}

Images (a-f) in Figure 12 show the microstructure of the friction surface of a composite disc in brake- $\mathrm{H}$, intercepted after various numbers of braking execution in water spray. The transferred materials deposited at the bedded stage were largely wiped off, and $\mathrm{SiC}$ regions were subjected to continuous polishing.

Compared to the friction surface after bedding shown in Figure 12(a)) after bedding, the $\mathrm{SiC}$, $\mathrm{Si}$ and $\mathrm{C}_{\mathrm{f}} / \mathrm{C}$ regions after first braking stop were all exposed under $\mathrm{OM}$ imaging conditions, as labelled in Figure 12(b), showing most of the deposited friction transfer materials, were not bonded strong enough on the surface. It is noted that some transferred materials were still left in Si regions, or inside voids on surface of $\mathrm{C}_{\mathrm{f}} / \mathrm{C}$ regions. The friction surface shows a rough morphology, largely defined by the tomography of the composite surface. As a key surface feature in $\mathrm{SiC}$ regions, the mechanical deformation kinks, developed during multiple braking in air, were still discernible.

After 3 braking stops, the change in $\mathrm{Si}$ and $\mathrm{C}_{\mathrm{f}} / \mathrm{C}$ regions was limited, but the mechanical deformation kinks became less discernible on the surface of $\mathrm{SiC}$ regions, as shown in Figure 12(c). After 8 braking stops, the surface of $\mathrm{SiC}$ became further smoothened without deformation kinks visible, apart from small voids, as shown in Figure 12(d). It is also noted 
that the exposed Si regions had transferred materials covered again up to this stage, showing dark-grey patches in $\mathrm{SiC}$ regions. As the braking continued, the polishing process just carried on, and $\mathrm{SiC}$ regions became even smoother, making voids on the surface become smaller and fewer, evidencing a significant polishing-off of the SiC surface without introducing any further surface cracking damage, as shown in Figure 12 (e-f). There was little change in all Si regions, as they were covered by transfer materials, as well as in all $\mathrm{Cf} / \mathrm{C}$ regions where no transferred materials firmly deposited, apart from powdery debris.

The brake disc of Brake-L experienced similar changes during braking under the same wet conditions. A representative image is shown in Figure 12(g) on the morphology of friction surface after 20 braking stops. $\mathrm{SiC}$ and $\mathrm{C}_{\mathrm{f}} / \mathrm{C}$ regions were clearly exposed; Si regions were covered by transferred materials.

The chemical composition on the friction surface was examined by EDXS, and representative spectrum acquired from $\mathrm{SiC}$ and $\mathrm{Si}$ is shown in Figure 13(a) and (b) respectively. In a $\mathrm{SiC}$ region, no other chemical elements were detected apart from $\mathrm{Si}$ and $\mathrm{C}$, indicating no transferred materials on $\mathrm{SiC}$ surface. In a $\mathrm{Si}$ region, $\mathrm{Cu} / \mathrm{Zn}$ and $\mathrm{O}$ detected along with $\mathrm{Si}$, indicating a cupper/zinc containing friction layer was maintained on the surface of Si with strong bonding. The lack of other main chemicals from the pad, such as Fe, implies that copper and silicon might have been fused together in a favoured manner, as noted in previous research $^{16}$. The enriched O peak implies that, not only the friction transfer layer might have been oxidised, but also plenty of oxygen dissolved in Si region as well, which was evidenced 
in reference 16. In a $\mathrm{C}_{\mathrm{f}} / \mathrm{C}$ region, $\mathrm{Si}, \mathrm{O}$ and $\mathrm{C}$ were the main chemical elements on the surface, indicating that the powdery debris were from the pad with chemical composition closer to silicates, which are used in pad as fillers.

The observation has demonstrated that $\mathrm{SiC} / \mathrm{Si}$ regions were the main load bearing, or friction contact, regions on a composite brake disc surface. Whilst some carbon fibres might have contributed the friction contact area, the fraction was relatively small, and is not accounted in the following analysis, as a approximation. Hence, the real pressure applied on the contact regions should be largely determined by the fraction of $\mathrm{SiC} / \mathrm{Si}$ regions on a friction surface. $\mathrm{By}$ using the real pressure, rather than the nominal pressure, the Stribeck curves can be re-plotted. Representative ones are shown in Figure 10(c). From this plot, we can infer that the higher coefficient for Brake-L in spray water environment is largely due to the higher contact pressure on friction plateaus during braking, comparing to those in Brake- $\mathrm{H}$, as indicated by the nearly linear trend of the shaded straight bar.

As shown above, $\mathrm{SiC} / \mathrm{Si}$ regions were the main friction contact on surface of a ceramic composite disc to govern the friction performance. Therefore, the boundary friction conditions must be associated to the surface topography in these regions. During braking, two phenomena, removal of transferred materials and surface polish, observed on surface of these regions can reduce boundary friction and concurrently reinforce hydrodynamic friction. First, the remove of friction transfer materials could change either adhesion or conformability between friction surfaces of pad and disc, or both, due to the chemicals on the friction surface become more inert 
and the increase of surface Young modulus. Secondly, the polish can directly reduce the height of asperities in these regions, making boundary contact less likely due to pressures on each asperity is reduced, and hydrodynamic friction becomes more sustainable even under relatively lower sliding speed. This is deemed to be the main reason for the observation that a gradual fall of friction coefficient for a braking stop when the braking stop number increased in water spray environment, as shown in regime-I in Figure 8.

\section{Summary}

A comparative study of friction performance through consecutive braking a disc against an organic pad under the same braking conditions that are closer to brakes in automobiles, a stable friction coefficient is achieved in ambient air environment for a brake consisting of a $\mathrm{C}_{\mathrm{f}} / \mathrm{C}-\mathrm{SiC}$ composite disc with high fraction of $\mathrm{SiC} / \mathrm{Si}(\sim 53.1 \%)$, and another one with low fraction of $\mathrm{SiC} / \mathrm{Si}(\sim 17.7 \%)$. The level of average friction coefficient for a braking stop is 0.52 for the brake with high fraction of $\mathrm{SiC} / \mathrm{Si}$ and 0.4 for the one with low fraction. Contribution to the friction measurements is largely determined by the friction contact regions during braking. Observation and analysis show that, after bedding, all SiC/Si regions, and about 50\% $\mathrm{C}_{\mathrm{f}} / \mathrm{C}$ regions become in friction contact to provide friction force through an adhesion mechanism. Friction contact surface in $\mathrm{SiC} / \mathrm{Si}$ regions includes exposed $\mathrm{SiC}$, deposited transfer materials in crevices and voids, and transferred friction layer chemically bonded in $\mathrm{Si}$ areas; that in $\mathrm{Cf} / \mathrm{C}$ regions comprises exposed carbon fibres and deposited friction transfer layer. $\mathrm{SiC} / \mathrm{Si}$ fraction in a ceramic composite does not provide proportional contribution to 
friction coefficient of a braking stop at after bedding. The brake with higher $\mathrm{SiC} / \mathrm{Si}$ content takes more braking stops to achieve stable friction, but the reason behind remains unclear yet.

When the bedded brakes are tested in water spray environment, the friction coefficient for a braking stop immediately drops to a level $<0.2$; further repeated braking operation brings the level further down to $<0.1$. The mechanism by which a much lower friction coefficient is achieved for the ceramic composite brakes is due to the introduction of hydrodynamic friction into boundary friction when water is involved in the braking process, i.e. a mixed friction mode is given. Examination of friction surfaces shows that the hydrodynamic friction is strongly associated to $\mathrm{SiC}$ regions on friction surface. A continuous polishing of these regions by the repeated braking and a removal of friction transfer layer deposited in $\mathrm{C}_{\mathrm{f}} / \mathrm{C}$ regions further reinforce the hydrodynamic process, which leads to a continuous fall of friction coefficient when more braking stops are applied in water spray environment. Comparative study shows that the brake consisting of high $\mathrm{SiC}$ gives $\sim 50 \%$ lower friction coefficient for each braking stop than the one with low $\mathrm{SiC}$ content. Analysis demonstrates that reduction of $\mathrm{SiC}$ leads to a higher real normal pressure that is applied on friction contact regions during friction, and hydrodynamic lubrication is therefore reduced.

\section{Acknowledgment}

We are very grateful to the Technology Strategy Broad (TSB), UK for providing financial 
support for this research, and a number of industry partners for providing support and helpful discussion. GB would also like to gratefully acknowledge Loughborough University for providing additional financial support for his $\mathrm{PhD}$ study. 


\section{Reference}

${ }^{1}$ Krenkel W, Heidenreich B, Renz R. C/C-SiC composites for advanced friction system. Adv Eng Mater 2002; 4: 427-36.

2 Jang H, Ko, K, Kim SJ, Basch, RH, Fash JW. The effect of metal fibres on the friction performance of automotive friction materials. Wear 2004; 256: 406-414.

${ }^{3}$ Eriksson M, Jakobson S. Tribological surface of organic brake pads. Tribol Intrt 2000; 33:817-827.

${ }^{4}$ Osterle W, Urban I. Friction layers and friction films on PMC brake pads. Wear 2004; 257: 215-226.

${ }^{5}$ Osterle W, Deutsch C, Gradt T, Orts-Gil G, Schneider T, Dmitriev AI. Tribological screening tests for the selection of raw materials for automotive brake pad formulations. Tribo Inter 2014; 73: 148-155

${ }^{6}$ Aleksendric D, Barton DC. Neural network prediction of disc brake performance. Tribo Inter 2009; 42: 1074-1080

${ }^{7}$ Cai P, Wang Y, Wang T, Wang Q. Effect of resins on thermal, mechanical and tribological properties of friction materials. Tribo Inter 2015; 87: 1-10

${ }^{8}$ Krenkel W, Berndt F. C/C-SiC composites for space applications and advanced friction systems. Mat Sci Eng 2005; A412: 177-181

${ }^{9}$ Blau PJ, Meyer III HM. Characteristics of wear particles produced during friction tests of conventional and unconventional disc brake materials. Wear 2003; 255: 1261-1269.

${ }^{10}$ Fan S, Zhang L, Cheng L, Tan G, Tang S. Effect of braking pressure and braking speed on the tribological properties of $\mathrm{C} / \mathrm{SiC}$ aircraft brake materials. Comp Sci Tech 2010; 70: 959-965.

${ }^{11}$ Fan S, Zhang L, Cheng L, Zhang J, Yang S, Liu H. Wear mechanisms of the C/SiC brake materials. Tribo Inter 2011; 44: 25-28.

${ }^{12}$ Wang Y, Wu H. Pindar D, Ferdani, P. Interaction between ceramic matrix composite and organic pad materials and its impact on the friction performance. SAE Inter 2011, 2011-01-2350

${ }^{13}$ Swarbrick AL, Wu H. Surface conditioning of carbon-fibre ceramic rotors against organic pads. SAE Inter 2012; 2012-01-1833.

${ }^{14}$ Wang Y, Wu H. Friction surface evolution of carbon fibre reinforced carbon/silicon carbide (Cf/C-SiC) composites. J Eu Ceram Soc 2010; 30: 3187-3201.

${ }^{15}$ Stadler Z, Krnel K, Kosmac T. Friction and wear f sintered metallic brake linings on a C/C-SiC composite brake disc. Wear 2008; 265: 278-285

${ }^{16}$ Wang Y, Wu H. Microstructure of friction surface developed on carbon fibre reinforced carbon-silicon carbide $\left(\mathrm{C}_{\mathrm{f}} / \mathrm{C}-\mathrm{SiC}\right)$. J Eu Ceram Soc 2012; 32:3509-3519. 
${ }^{17}$ Jacko MG, Trang PHS, Rhee SK. Wear debris compaction and friction film formation of polymer composites. Wear 1989; 133:23-38

${ }^{18}$ Stadler Z, Krnel K, Kosma T. Friction behaviour of sintered metallic brake pads on C/C-SiC composite brake disc. J Eu Ceram Soc 2007; 27:1411-1417.

${ }^{19}$ Brake Dynamometer Standard Committee: Surface Vehicle Recommended Practice. Dynamometer Globale Brake Effectiveness, SAE J2522, SAE International, SAE Technical Standards. Http://www.sae.org (2003).

${ }^{20}$ Blau PJ, McLaughlin JC. Effects of water films and sliding speed on the frictional behavior of truck disc brake materials. Trib Inter 2003; 36: 709-715.

${ }^{21}$ El-tayeb NSM, Liew KW. On the dry and wet sliding performance of potentially new frictional brake pad materials for automotive industry. Wear 2009; 266: 275-287.

${ }^{22}$ Limpert R. Brake Design and Safety, Society of Automotive Engineers. Wattendale, PA

${ }^{23}$ Eriksson M, Ergman F, Jacobson S. On the nature of tribologucal contact in automotive brakes. Wear 2002; 252:26-36

${ }^{24}$ Krenkel W. Cost effective processing of CMC composites by melt infiltration (LSI-process). Ceram Eng \& Sci Pro 2001; 23: 443-454.

25 Xu S, Qiao G, Li D, Yang H, Liu Y, Lu T. Reaction forming of silicon carbide ceramics using phenolic resin derived porous carbon preform. J Eu Ceram Soc 2009; 29: 2395-2402.

${ }^{26}$ Zhao DL, Yin HF, Luo F, Zhou WC. Microstructure and mechanical properties of 3D textile $\mathrm{C} / \mathrm{SiC}$ composites fabricated by chemical vapour infiltration. Adv Mat Res 2006; 11-12: 81-84.

27 Schulte-Fischedick J, Zern A, Mayer J, Ruhle M, Frieß, Krenkel W, Kochendorfer R. The morphology of silicon carbide in C/C-SiC composites. Mat Sci \& Eng 2002; 332: 146-152.

28 Margiotta JC, Zhang D, Nagle DC. Microstructural evolution during silicon carbide (SiC) formation by liquid silicon infiltration using optical microscopy. Int J of Ref Met \& Hard Mats 2010; 28: 191-197.

${ }^{29}$ Bowden FP, Tabor D. The Friction and Lubrication of Solids. Oxford University Press, Oxford (1964).

30 Spike HA. Mixed lubrication - an overview. Lub Sci 1997; 9:221-253.

${ }^{31}$ http://www.ddbst.com/ 


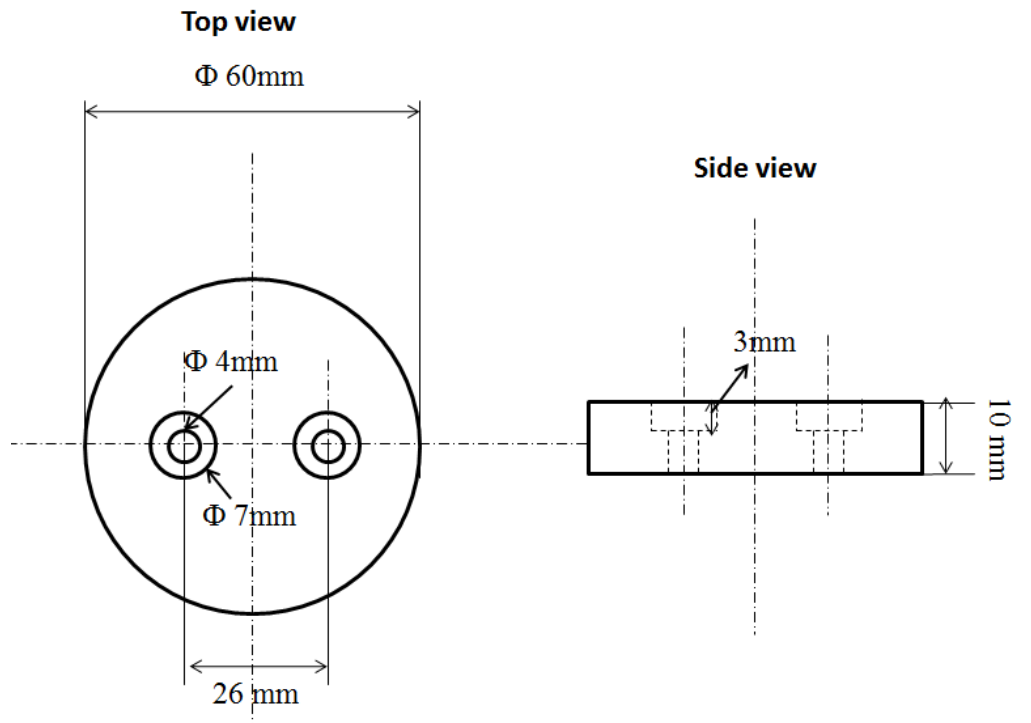

(a)
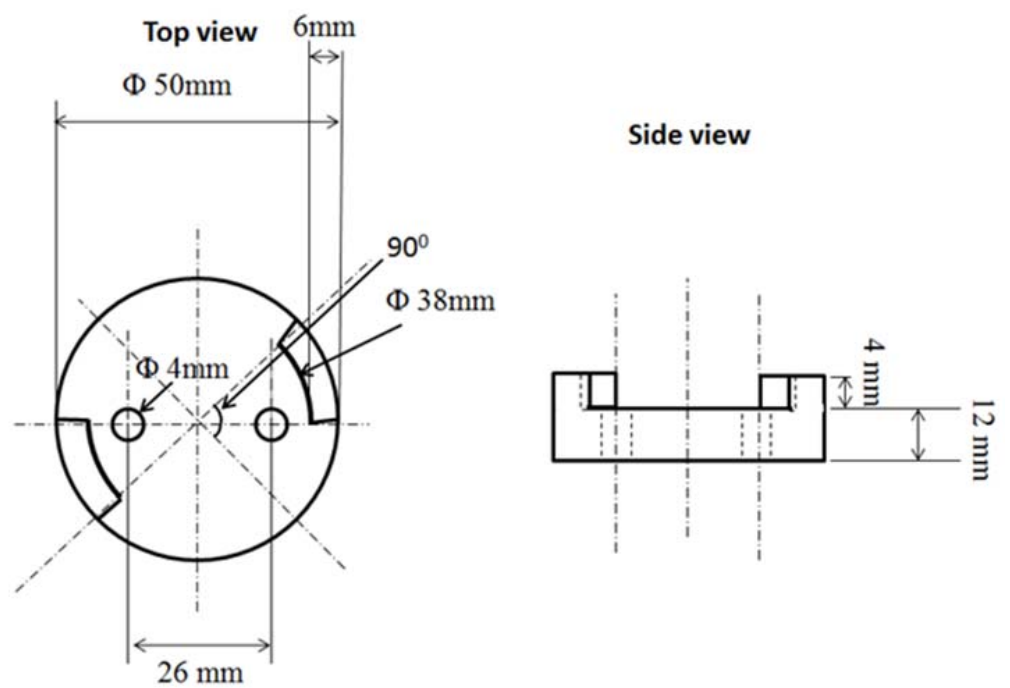

(b)

Figure 1 Drawing of (a) brake disc, and (b) pad used for braking study on a laboratoryscale dynamometer. 


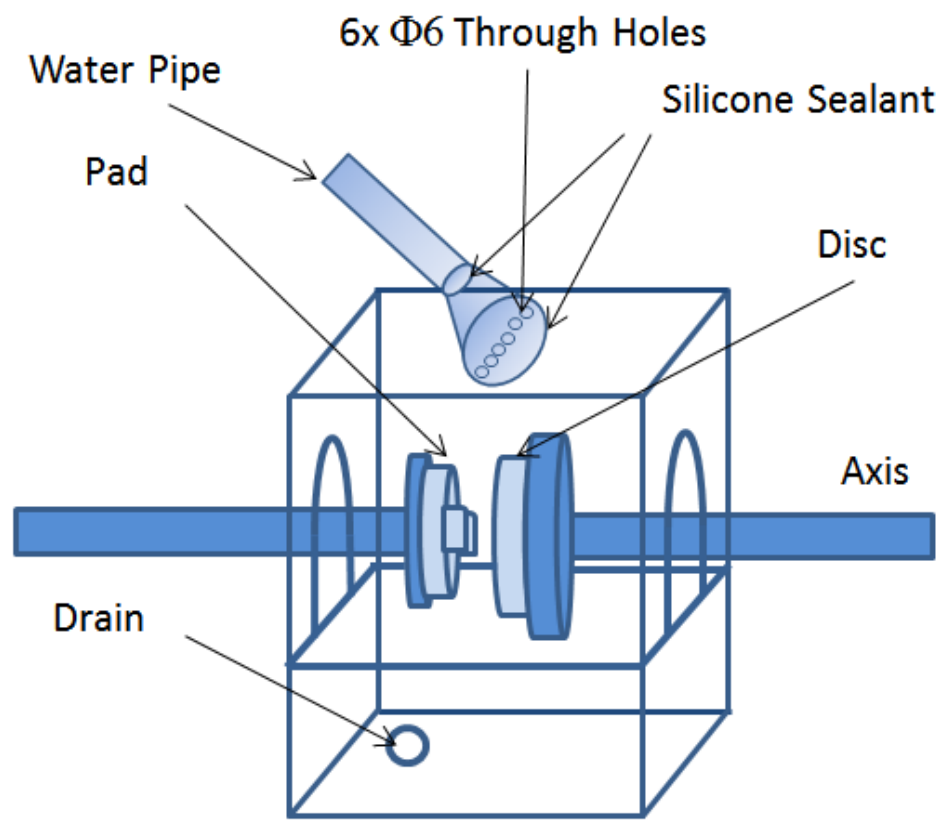

Figure 2 Schematically illustration of the water spray system attached to the braking test rig. 


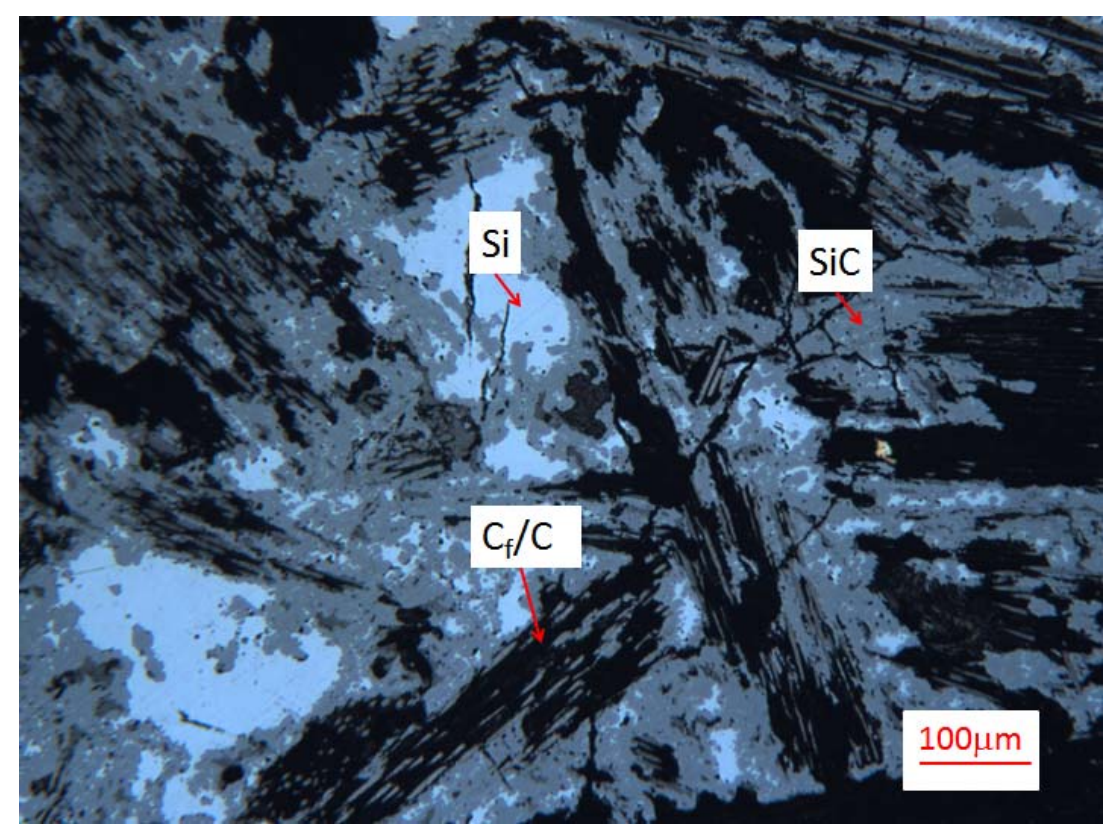

(a)

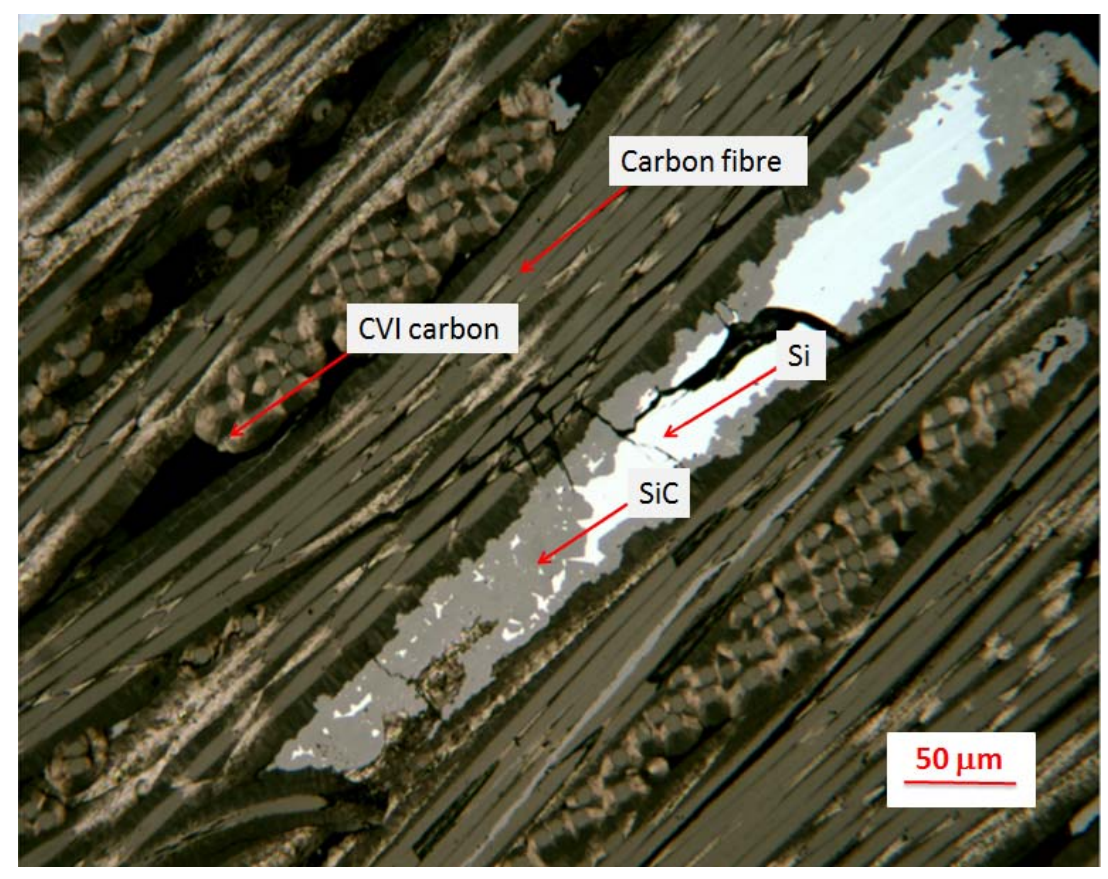

(b)

Figure 3 Optical microscopy images of as-polished surface of carbon ceramic composite disc in (a) Brake- $\mathrm{H}$, and (b) Brake-L. The constituents are labelled in the image. 


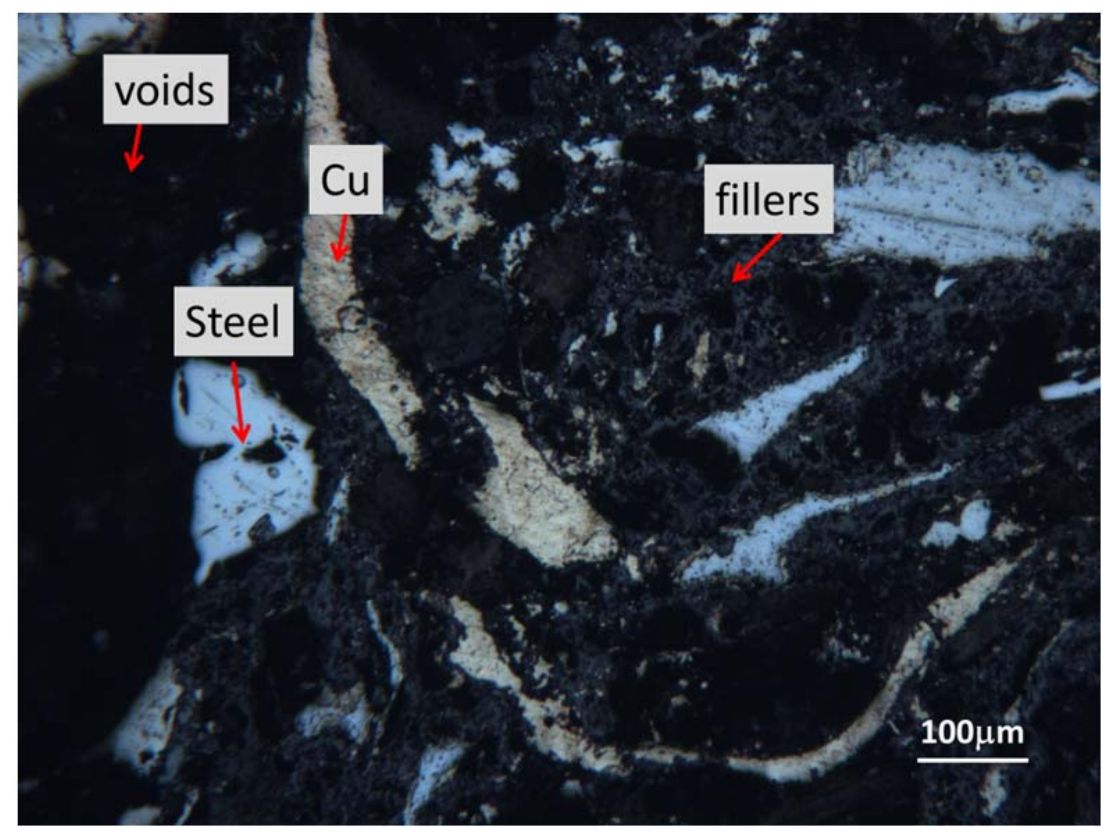

Figure 4 Optical microscopy images of as-polished surface of organic pad. The main constituents are labelled in the image. 


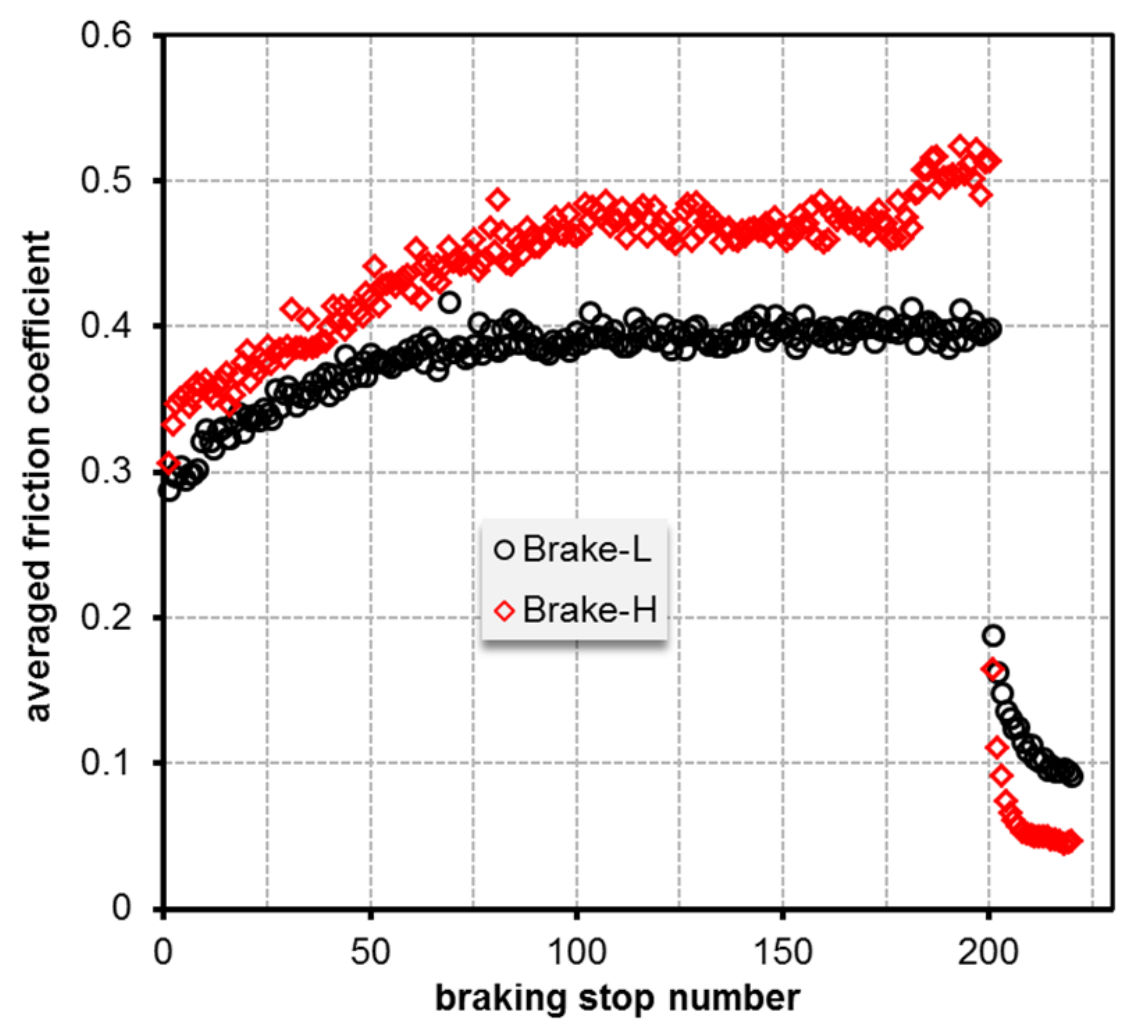

Figure 5 Averaged friction coefficient of each braking stop for two ceramic composite brake discs tested against same organic pad in ambient air from braking stop number 1 to 200, and in water spray from 201 to 215. 


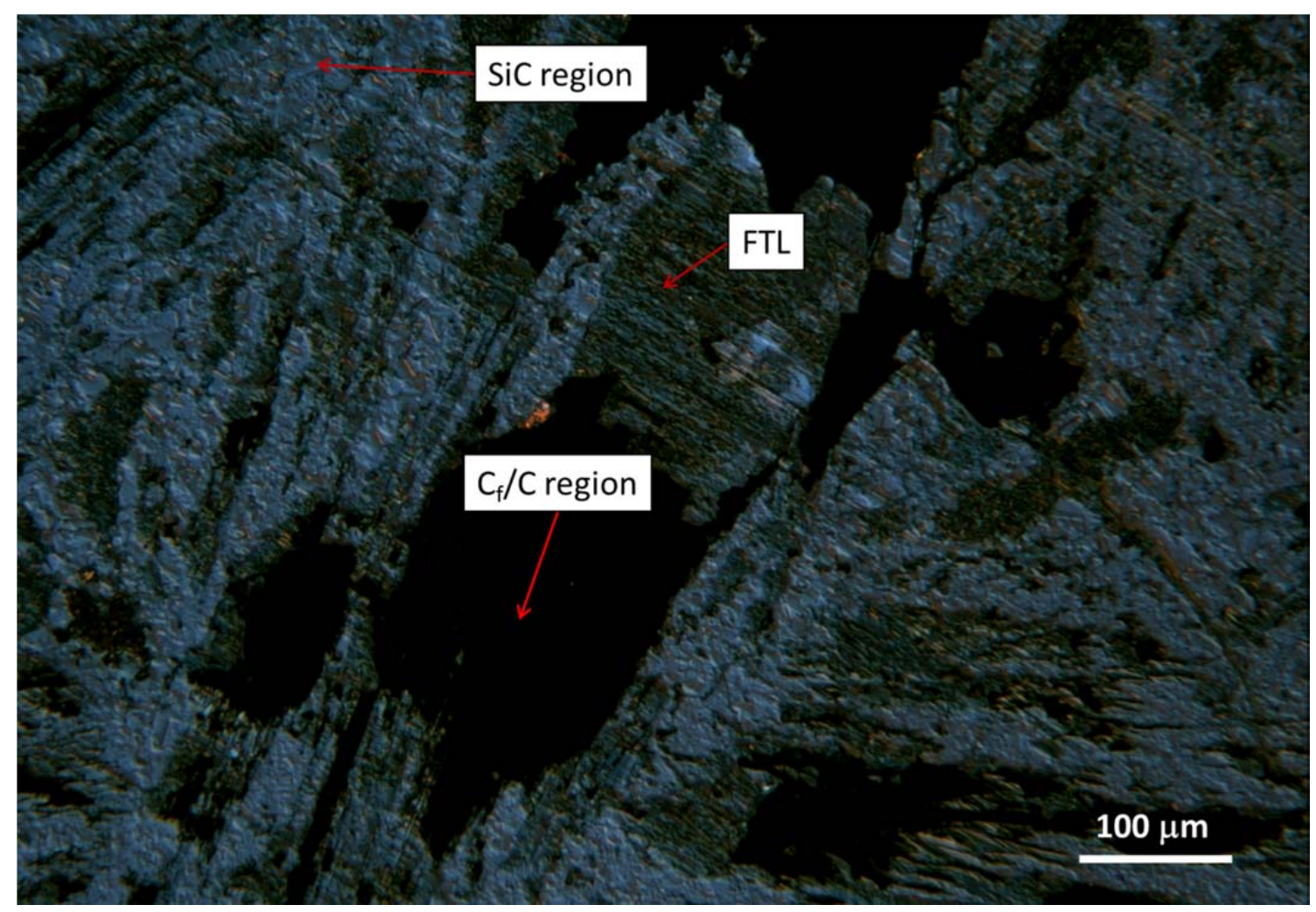

(a)

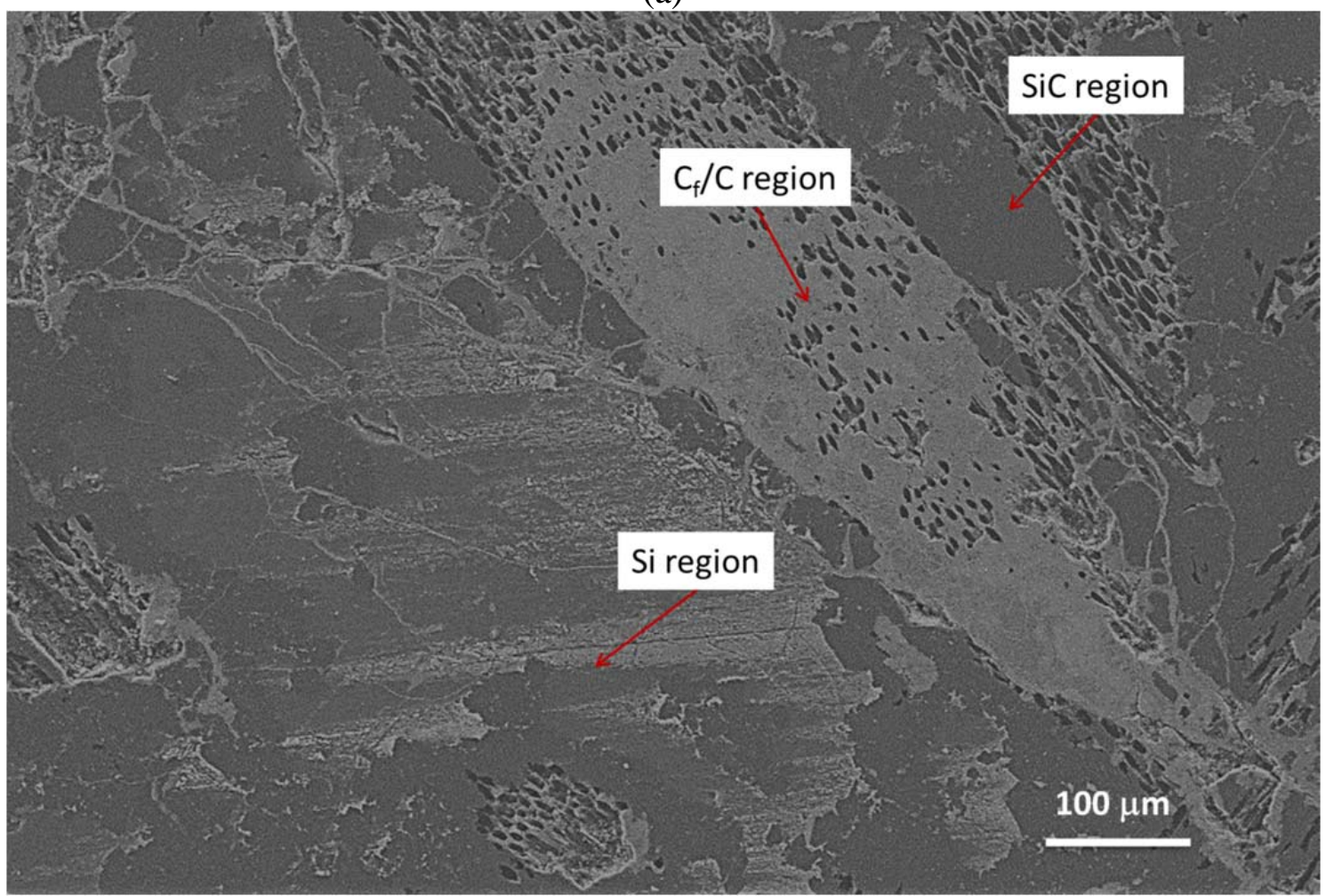

(b) 


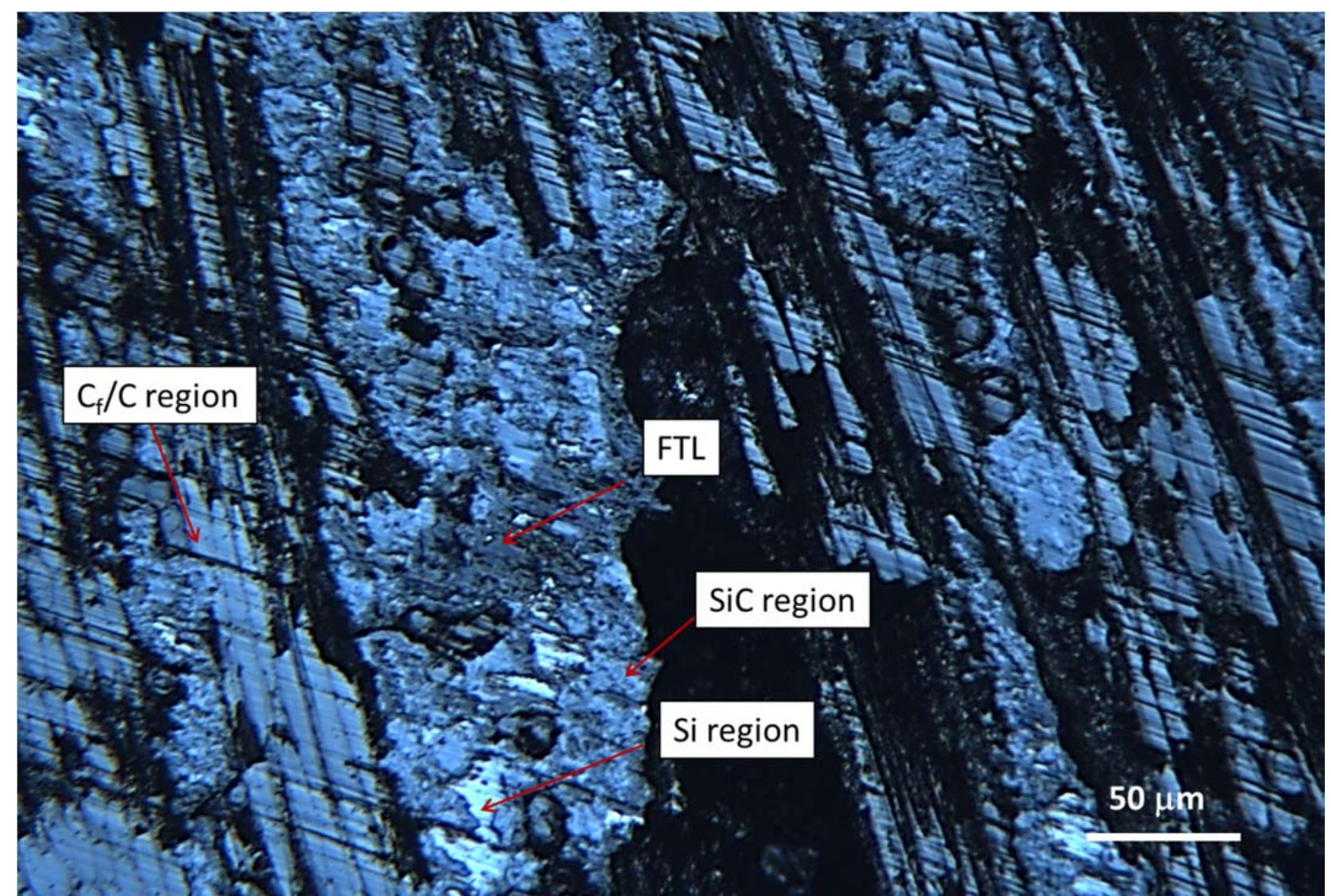

(c)

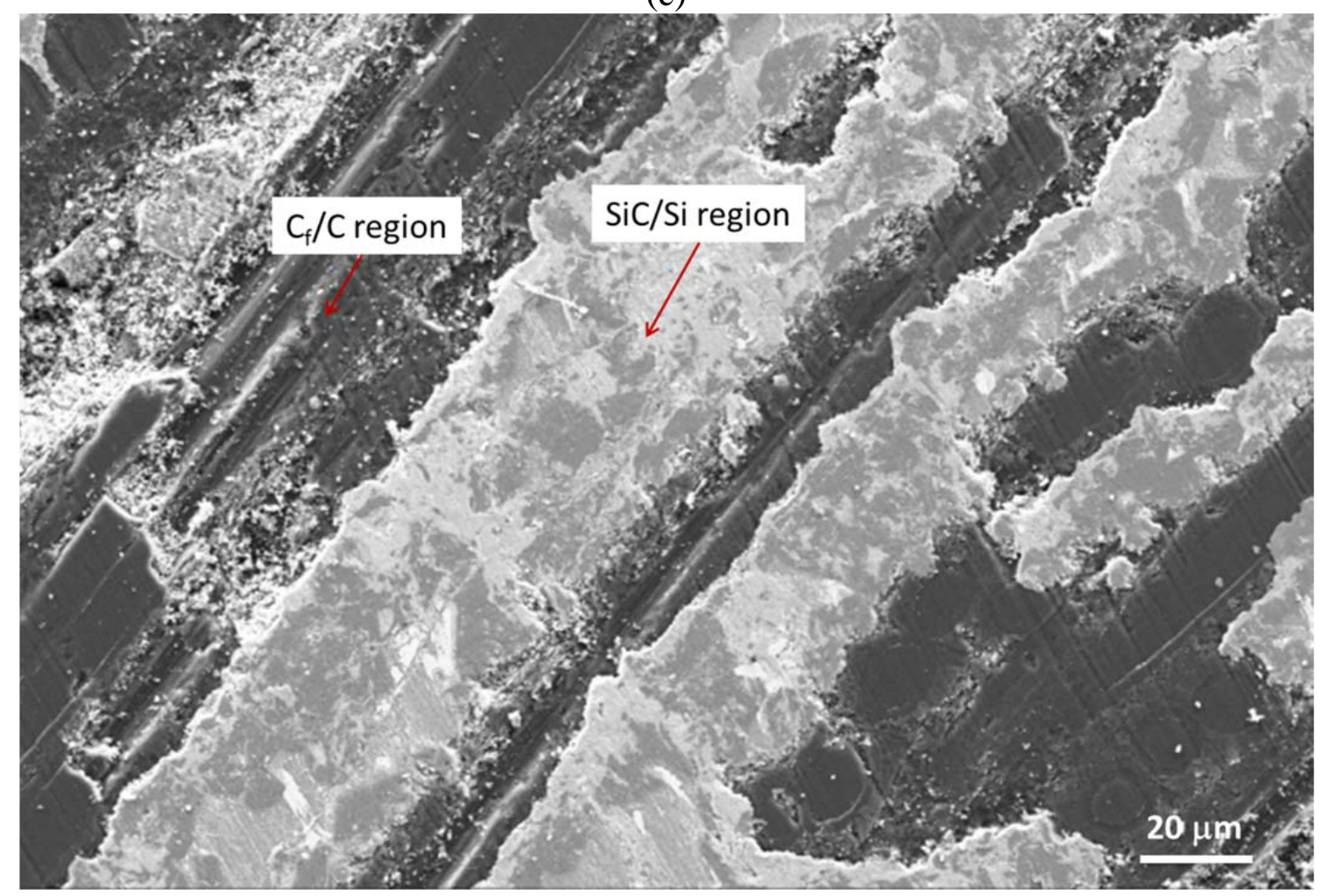

(d)

Figure 6 Representative OM (a and c)) and SEM (c and d)) images of friction surface of a $\mathrm{C}_{\mathrm{f}} / \mathrm{C}$-SiC composite brake disc, subjected 200 braking stops against an organic pad in ambient air for Brake-H (a-b) and Brake-L (c-d). Both brakes were fully bedded. 


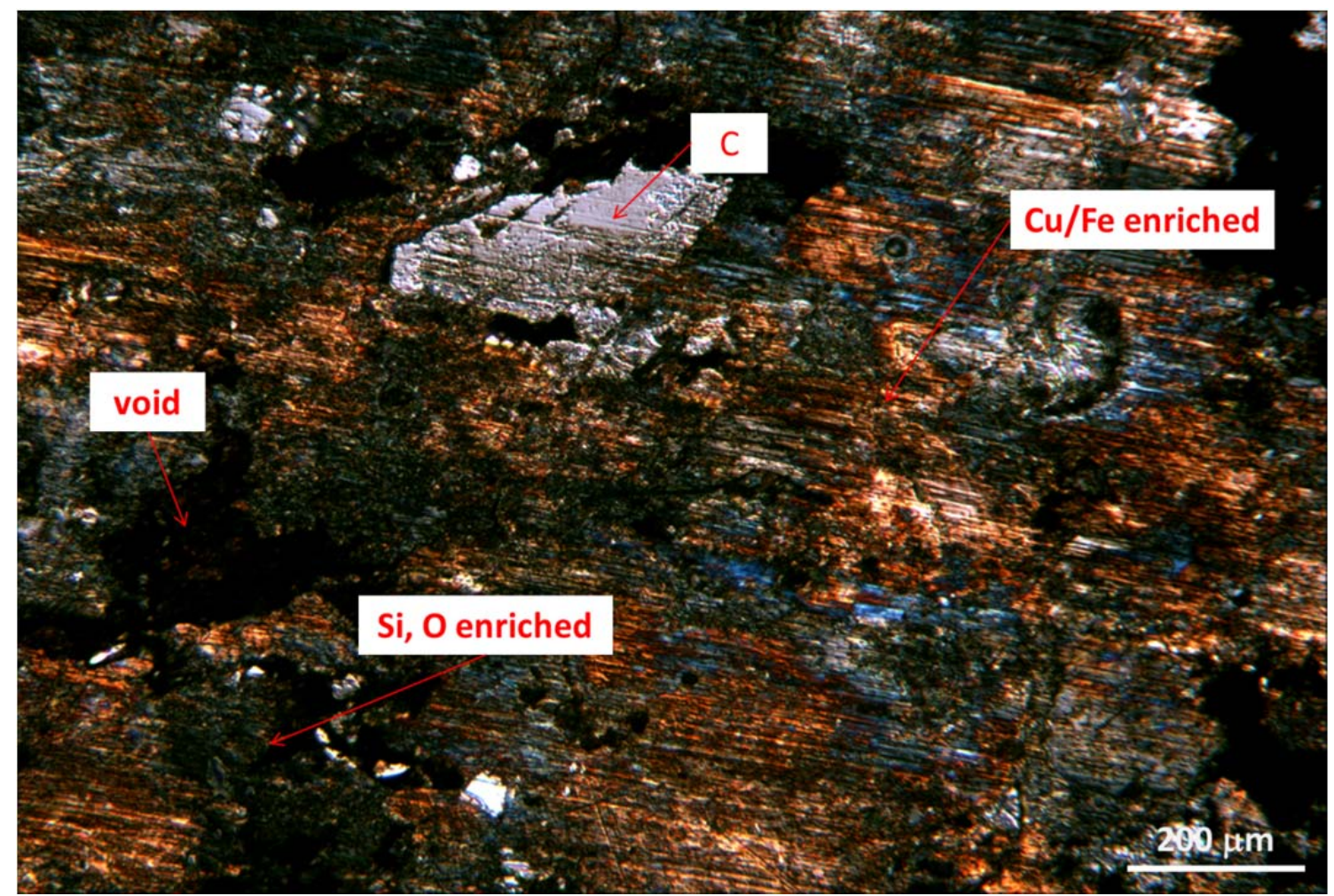

(a)

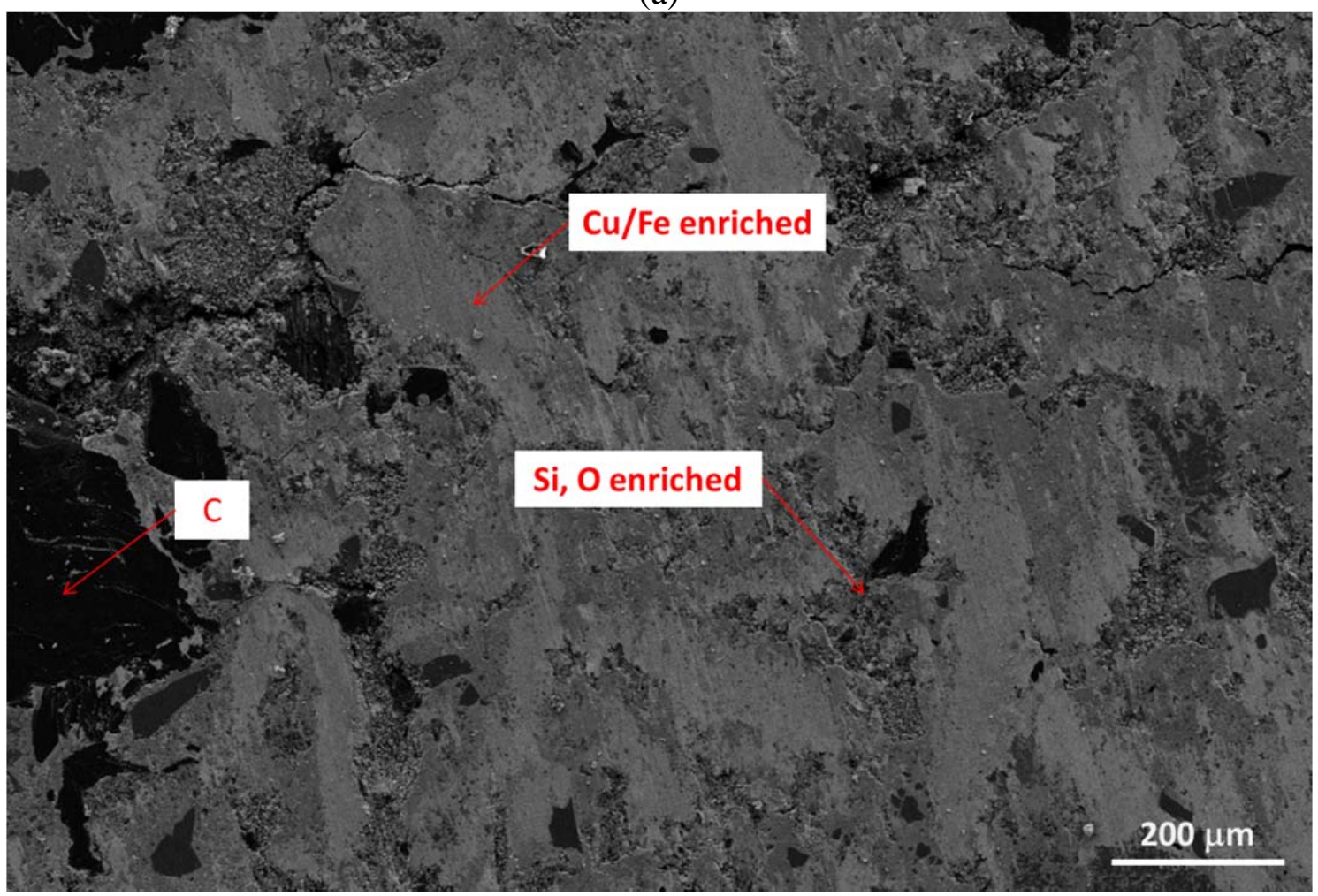

(b)

Figure $7 \quad$ Representative (a) OM and (b) SEM images of friction surface of an organic pad tested against a $\mathrm{C}_{\mathrm{f}} / \mathrm{C}-\mathrm{SiC}$ composite disc, subjected to 200 braking stops, in Brake-H. The primary chemicals in white grey, dark grey, and black region in SEM image include copper/iron enriched, silicon and oxygen enriched, and carbon respectively, and the corresponding regions are labelled in OM image. 



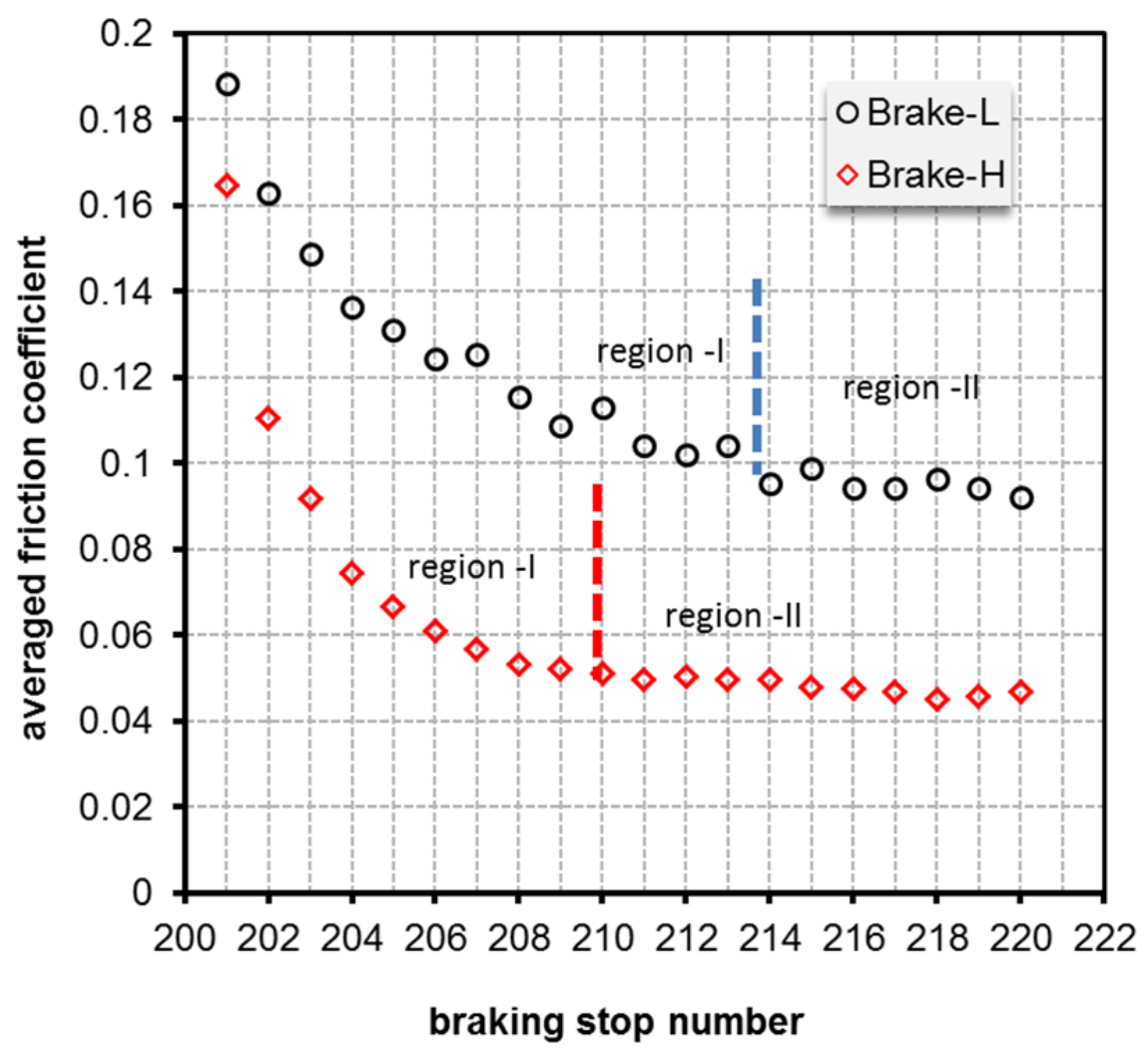

Figure 8 Averaged friction coefficient of each braking stop for two ceramic composite brake discs tested against same organic pad in water spray straight forward after bedding test in ambient air. 


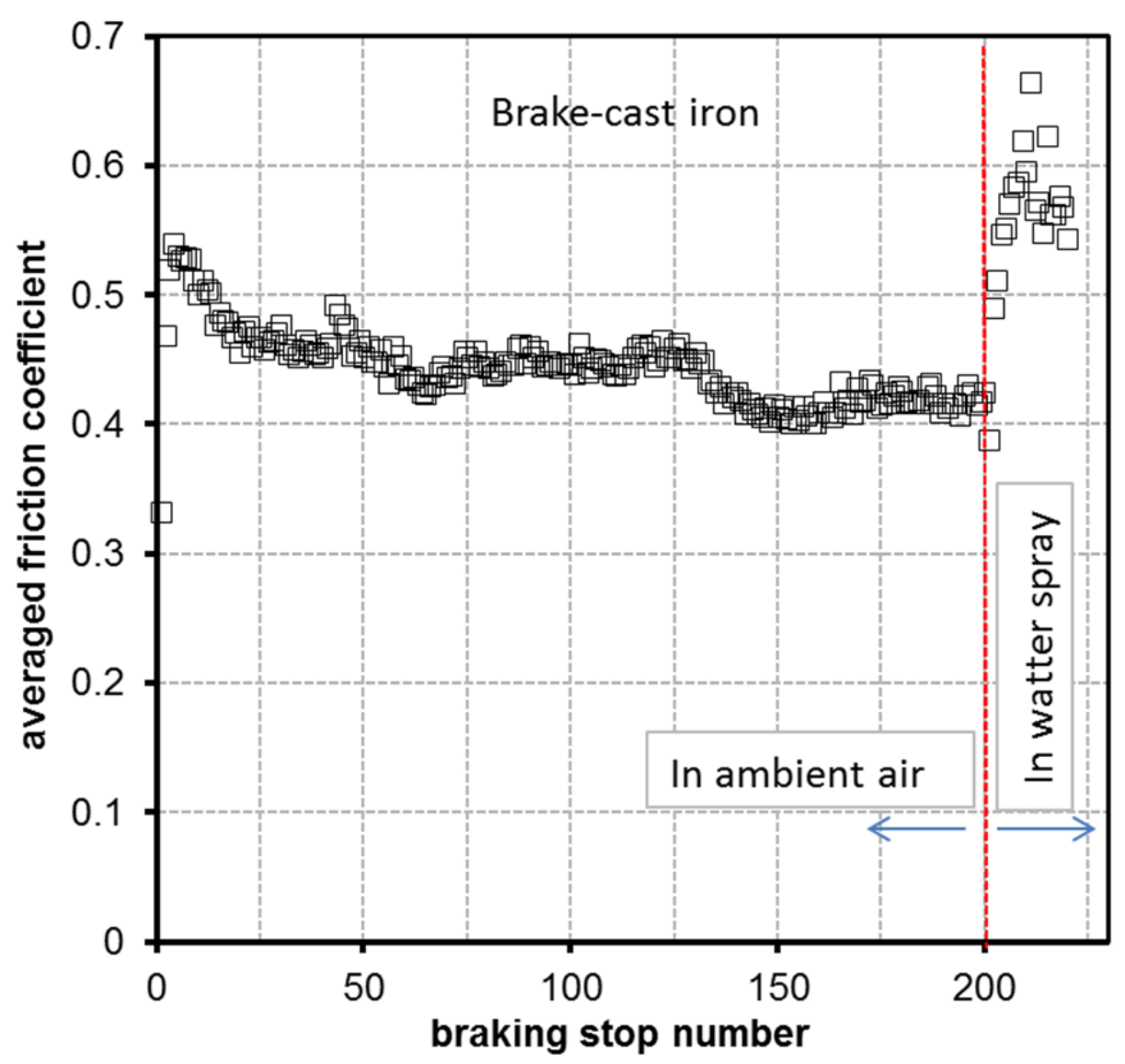

Figure 9 Averaged friction coefficient of each braking stop for a cost iron brake discs tested against an organic pad in ambient air from braking stop number 1 to 200, and in water spray from 201 to 220 . 

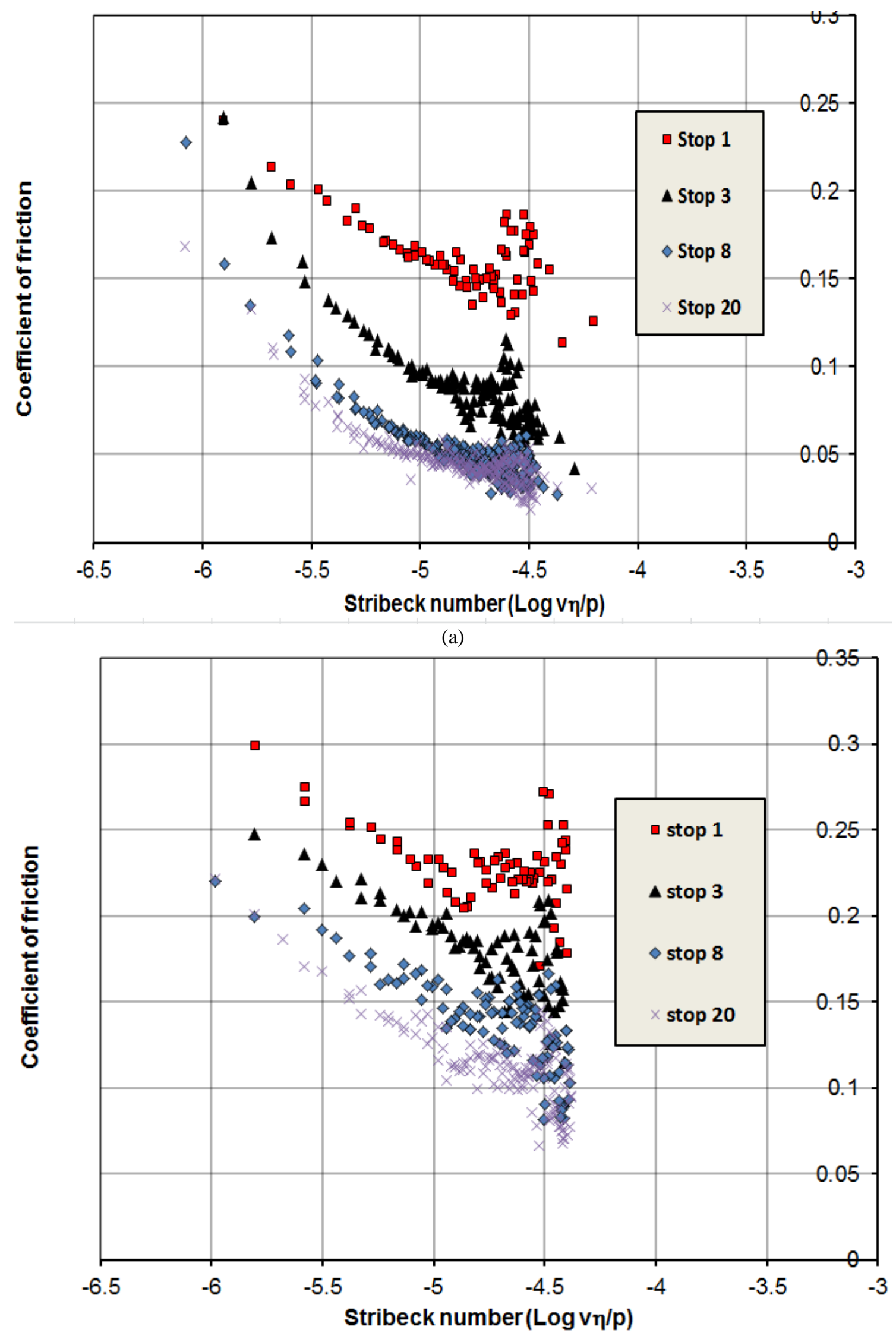

(b) 


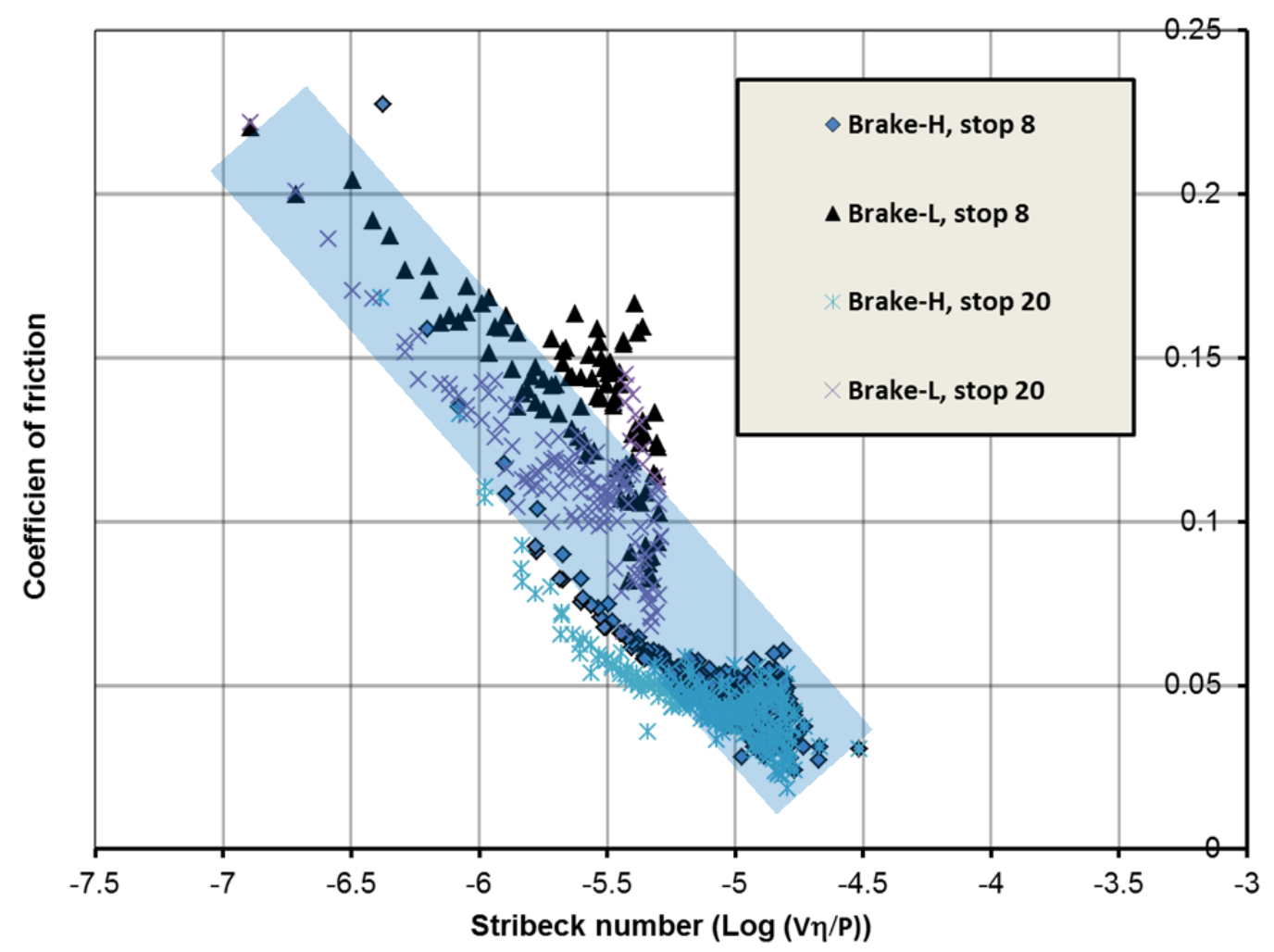

(c)

Figure 10 Representative plots of friction coefficient versus stribeck number Log Vך/P where $\mathrm{p}$ is the nominal pressure in (a) Brake-H and (b) Brake-L under water spray conditions. (c) friction coefficient versus Stribeck number $\log V \eta / P$ where $p$ is the estimated real pressure applied on $\mathrm{SiC/Si}$ regions. 


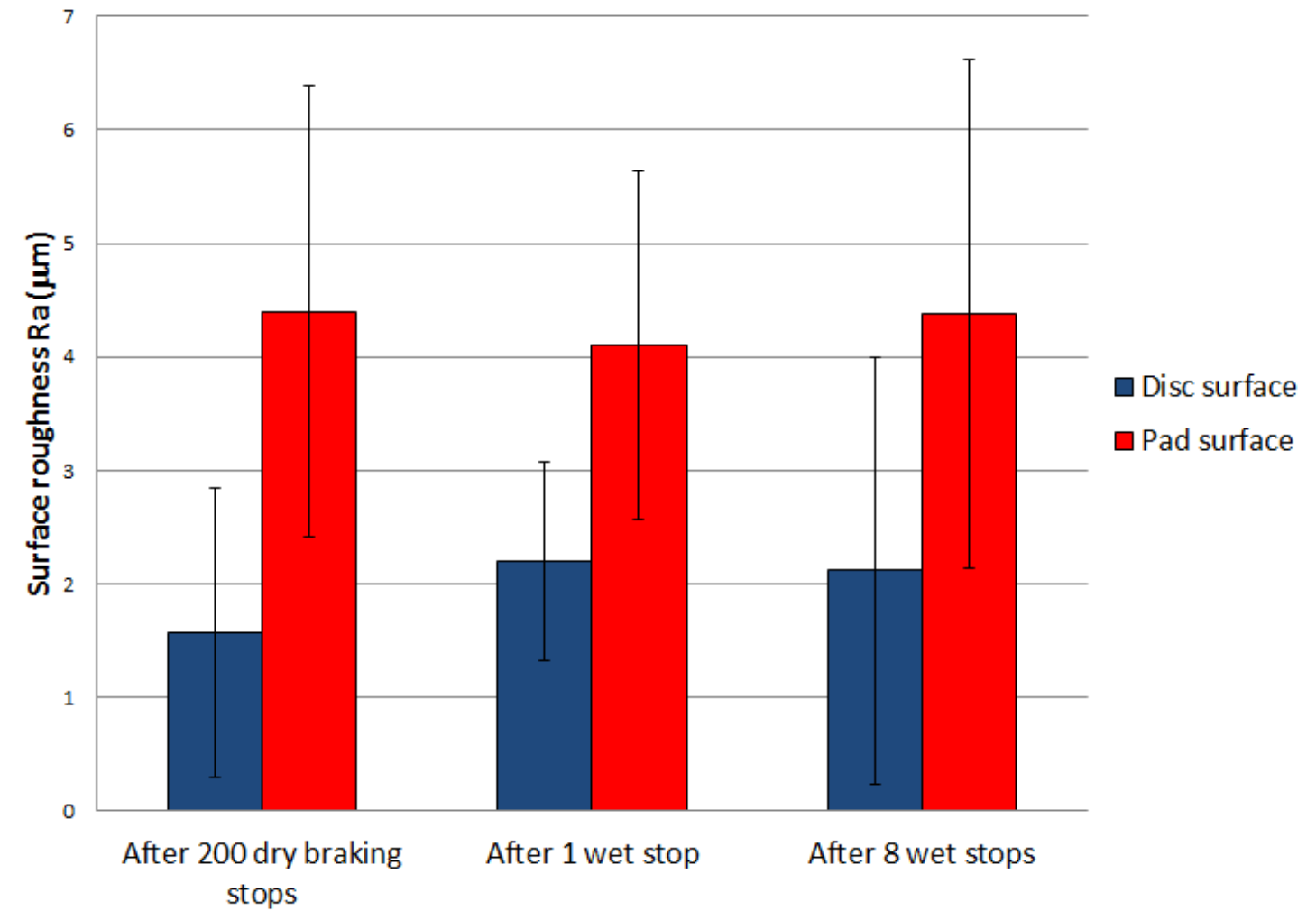

(a)

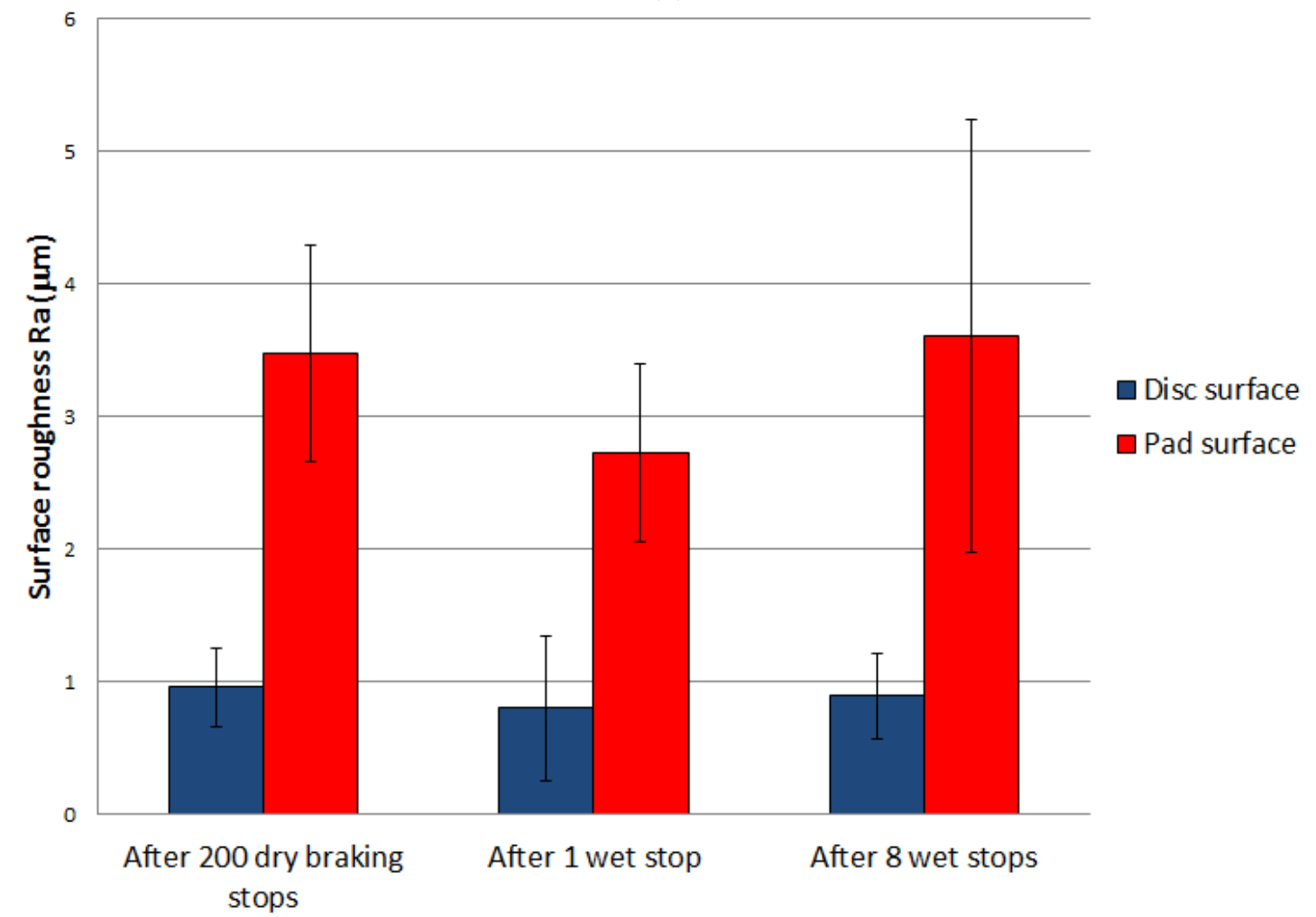

(b)

Figure 11 Roughness of Ra measured on the disc and pad fraction surfaces of (a) Brake$\mathrm{H}$ (a) and (b) Brake-L (b) after 200 braking stops in ambient air, and 1 and 8 stops in water spray. 


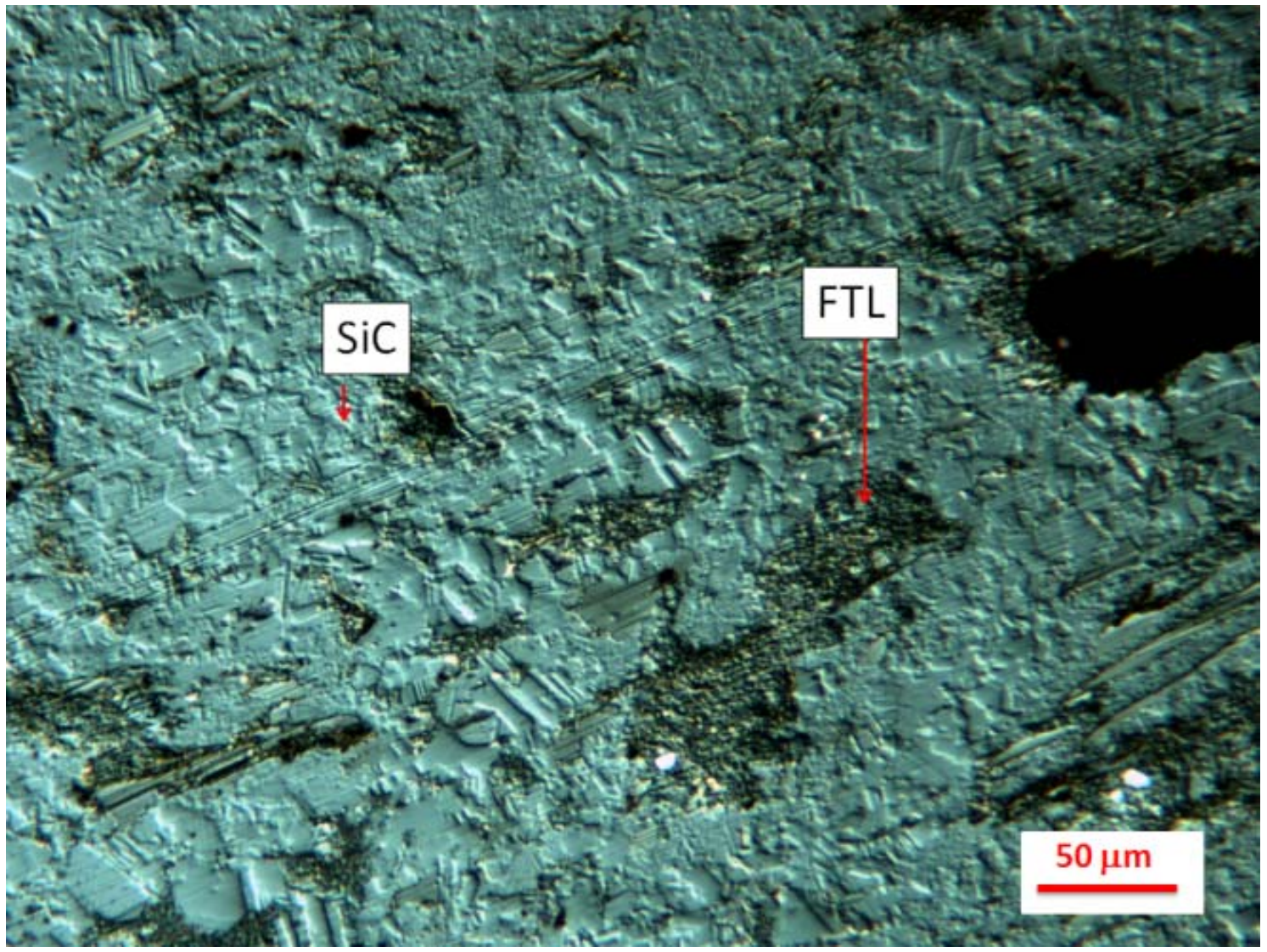

(a)

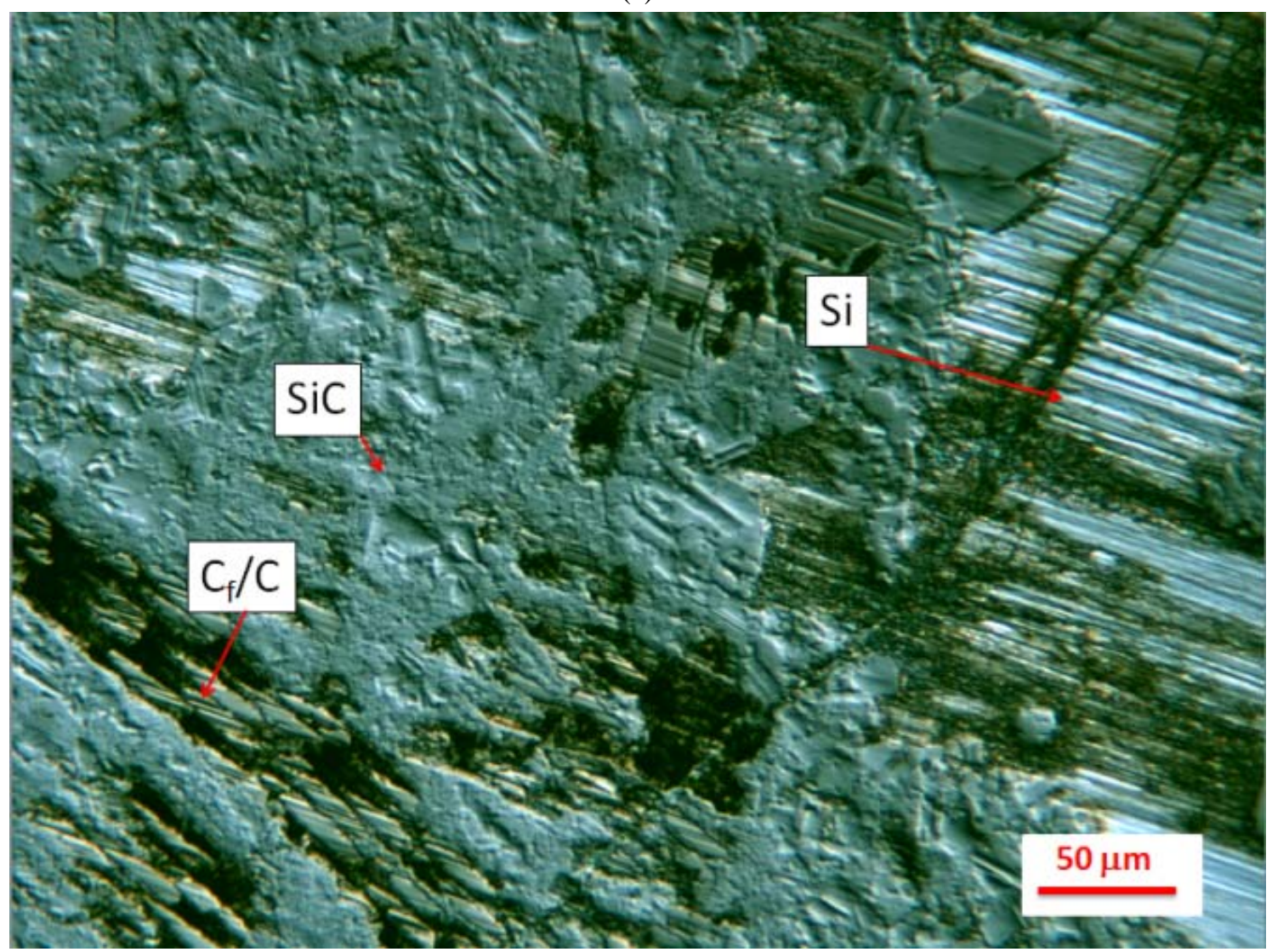

(b) 


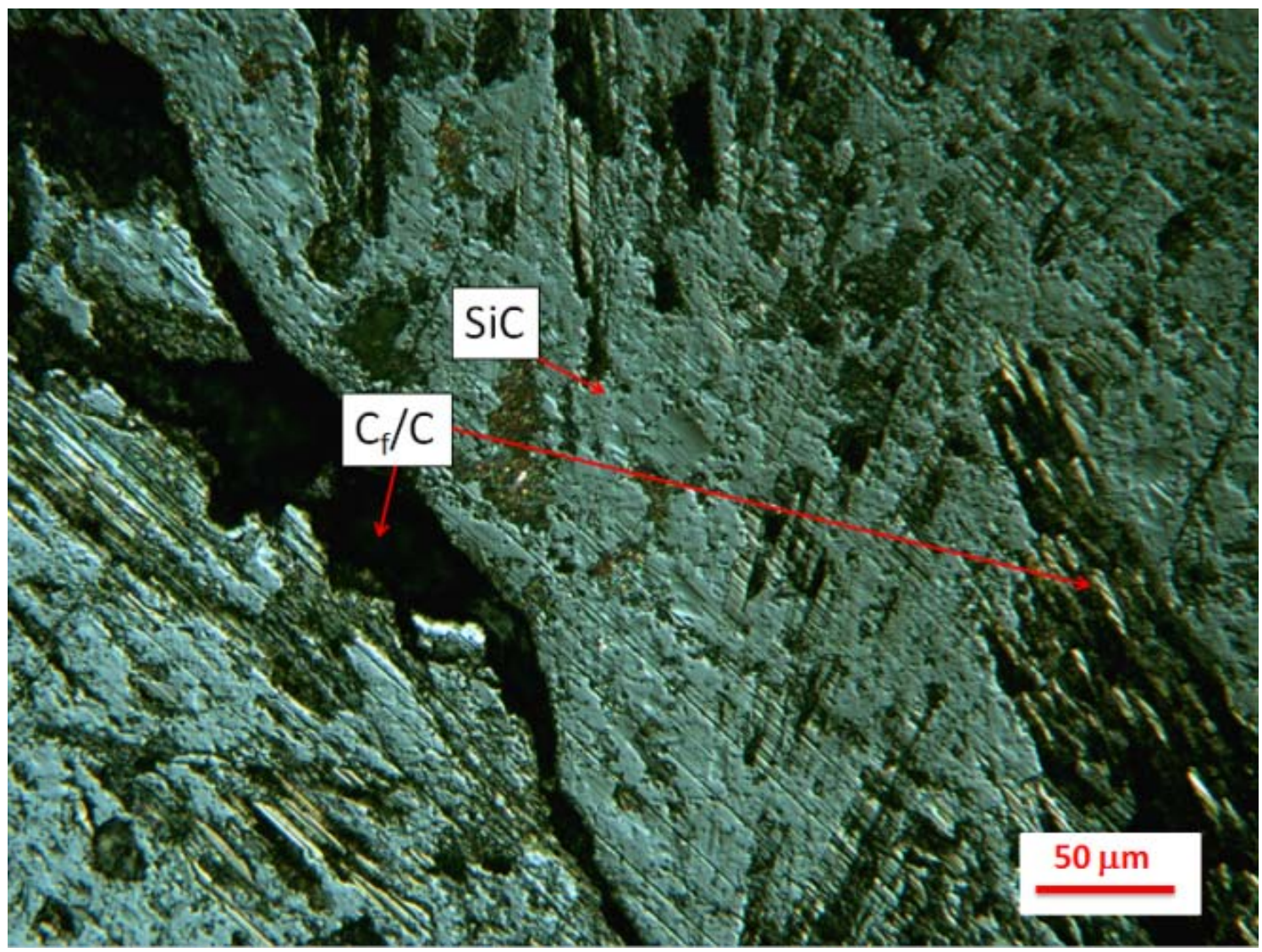

(c)

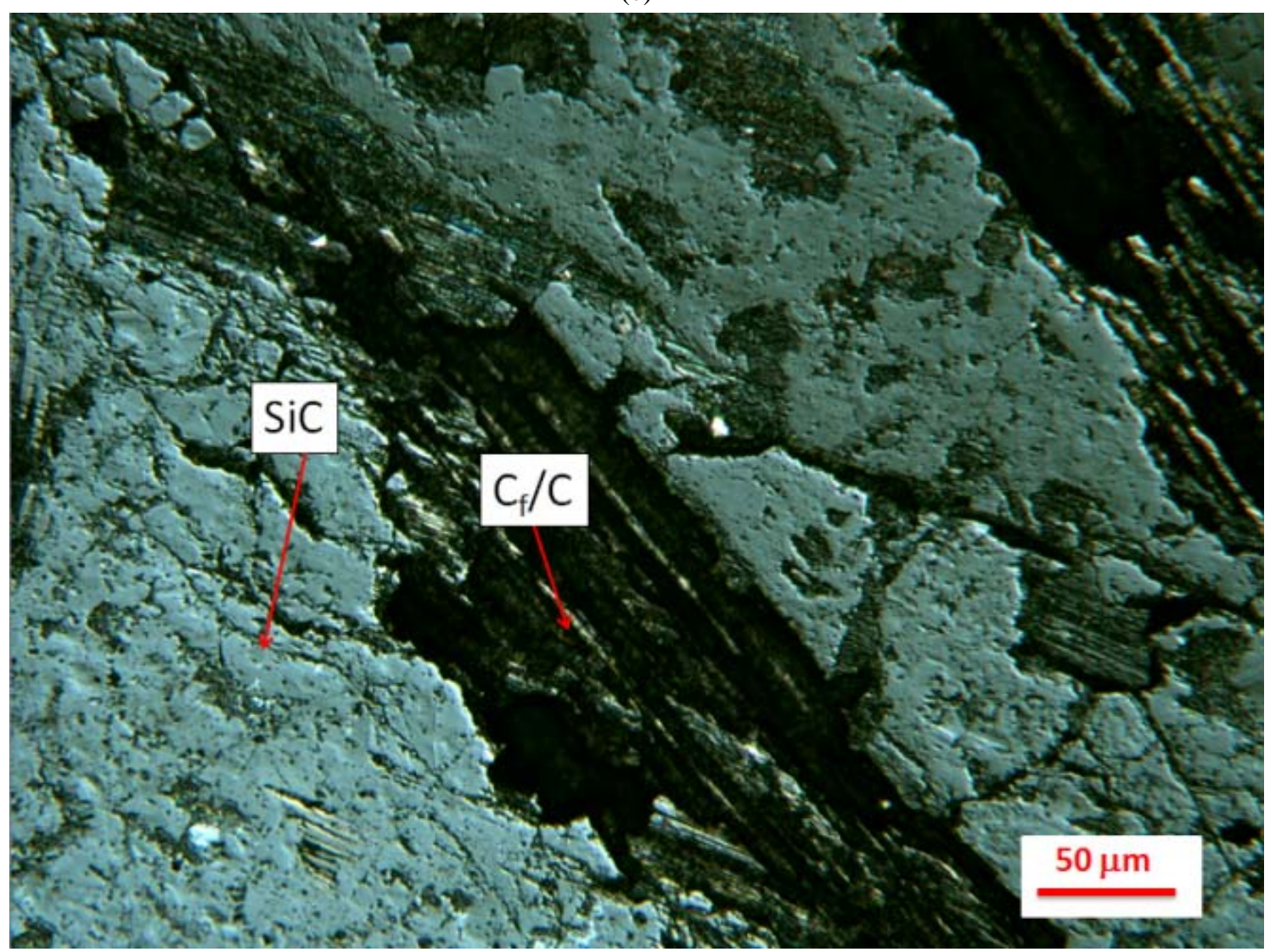

(d) 


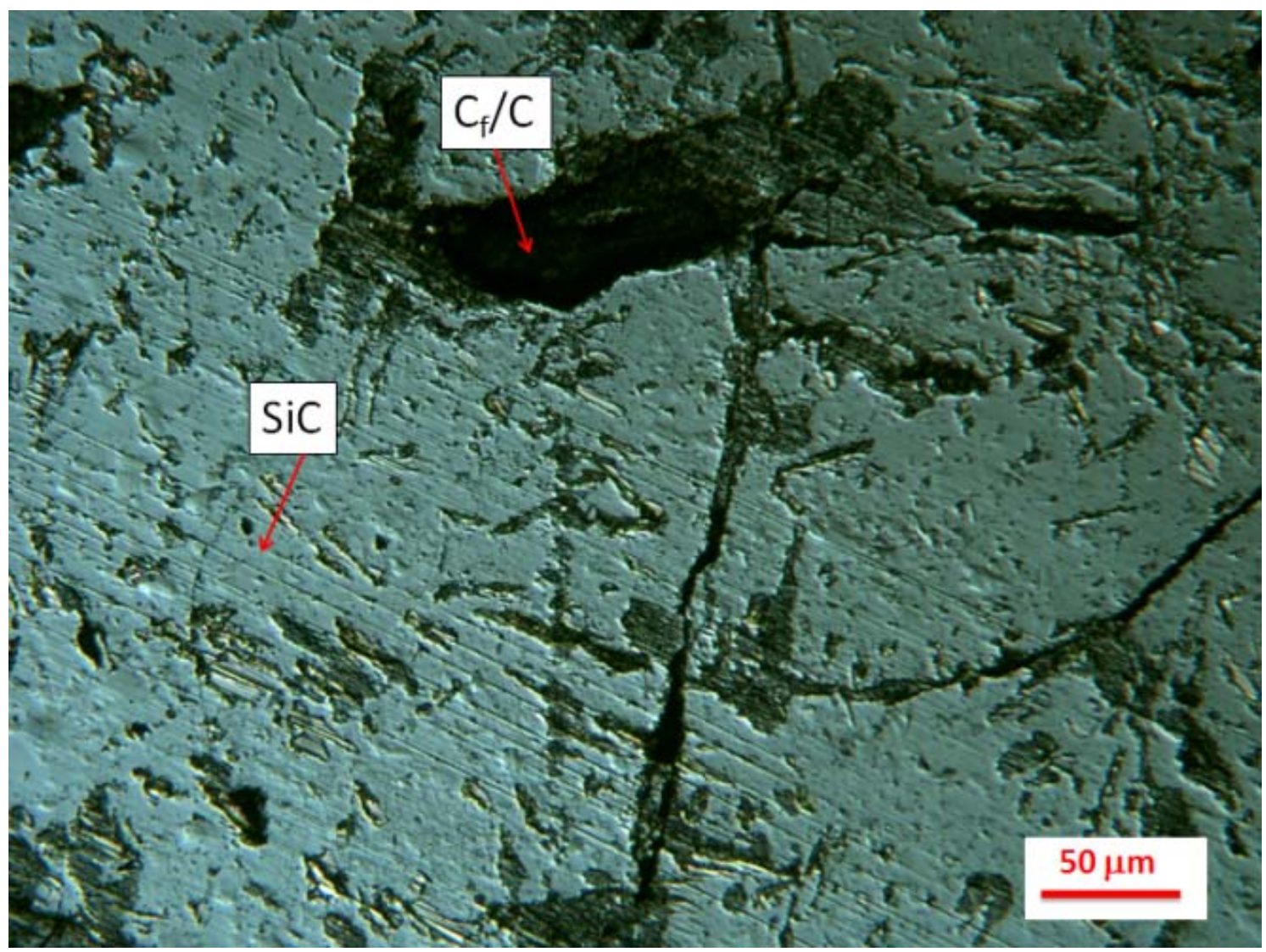

(e)

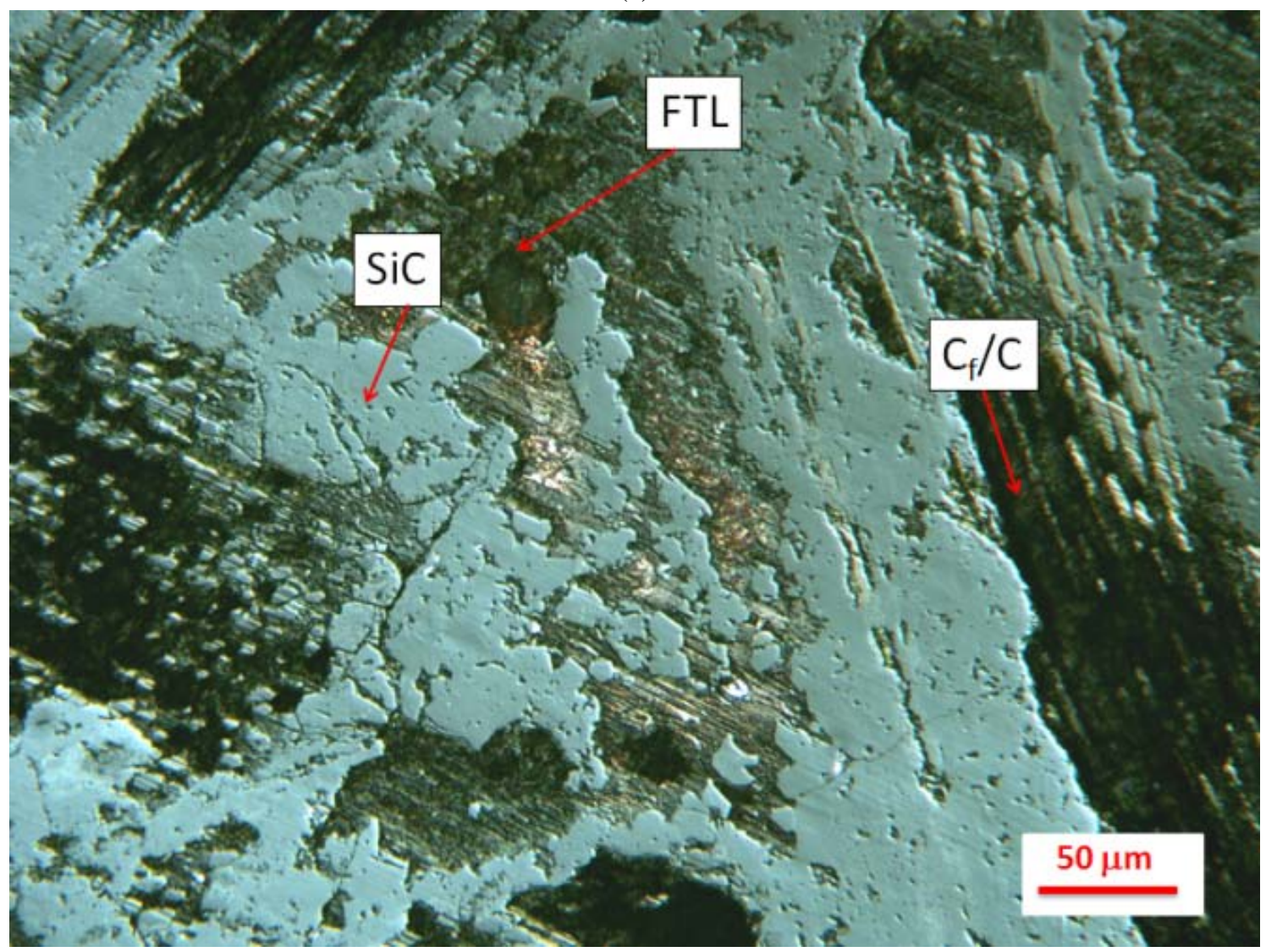

(f) 


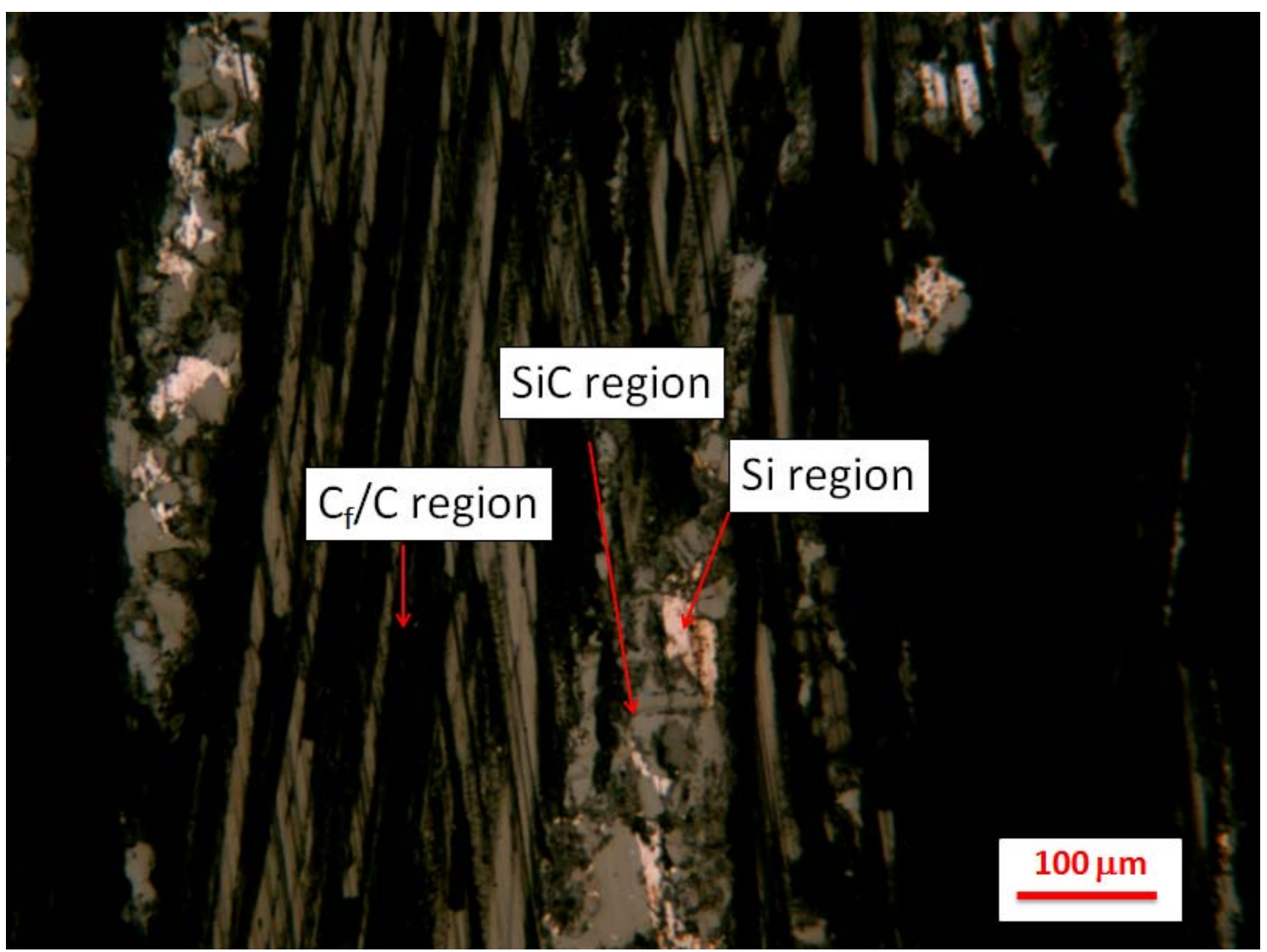

(g)

Figure 12 OM images of the friction surface developed on $\mathrm{C}_{\mathrm{f}} / \mathrm{C}$-SiC discs after different braking stop number under water spray conditions. (a) fully bedded friction surface before test in wet; (b)-(f) after 1, 3, 8, 12 and 20 braking stops, respectively, of disc friction surface of Brake-H in water spray environment. (g) OM image of disc friction surface of Brake-L after 20 braking stops in water spray environment. 


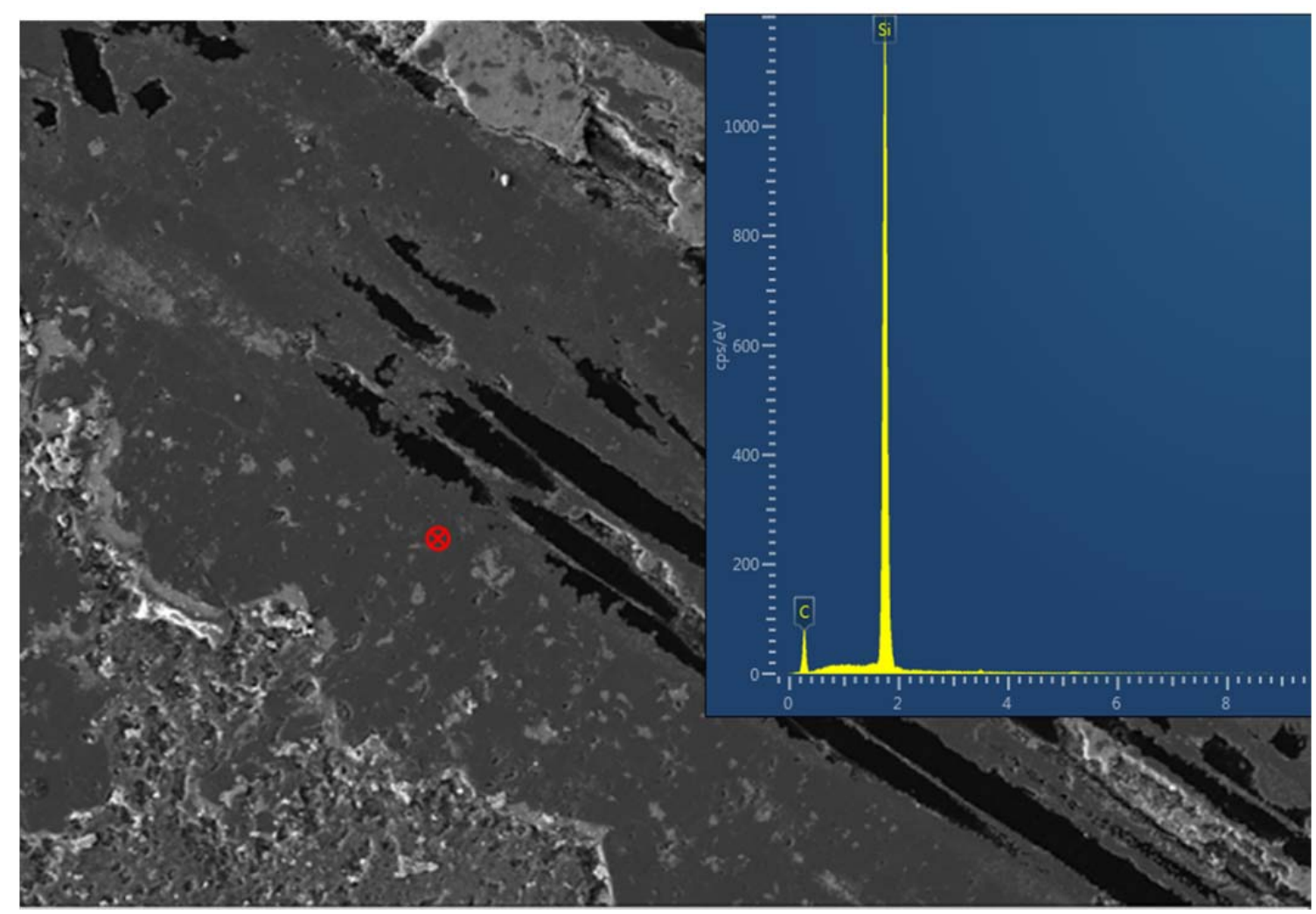

(a)

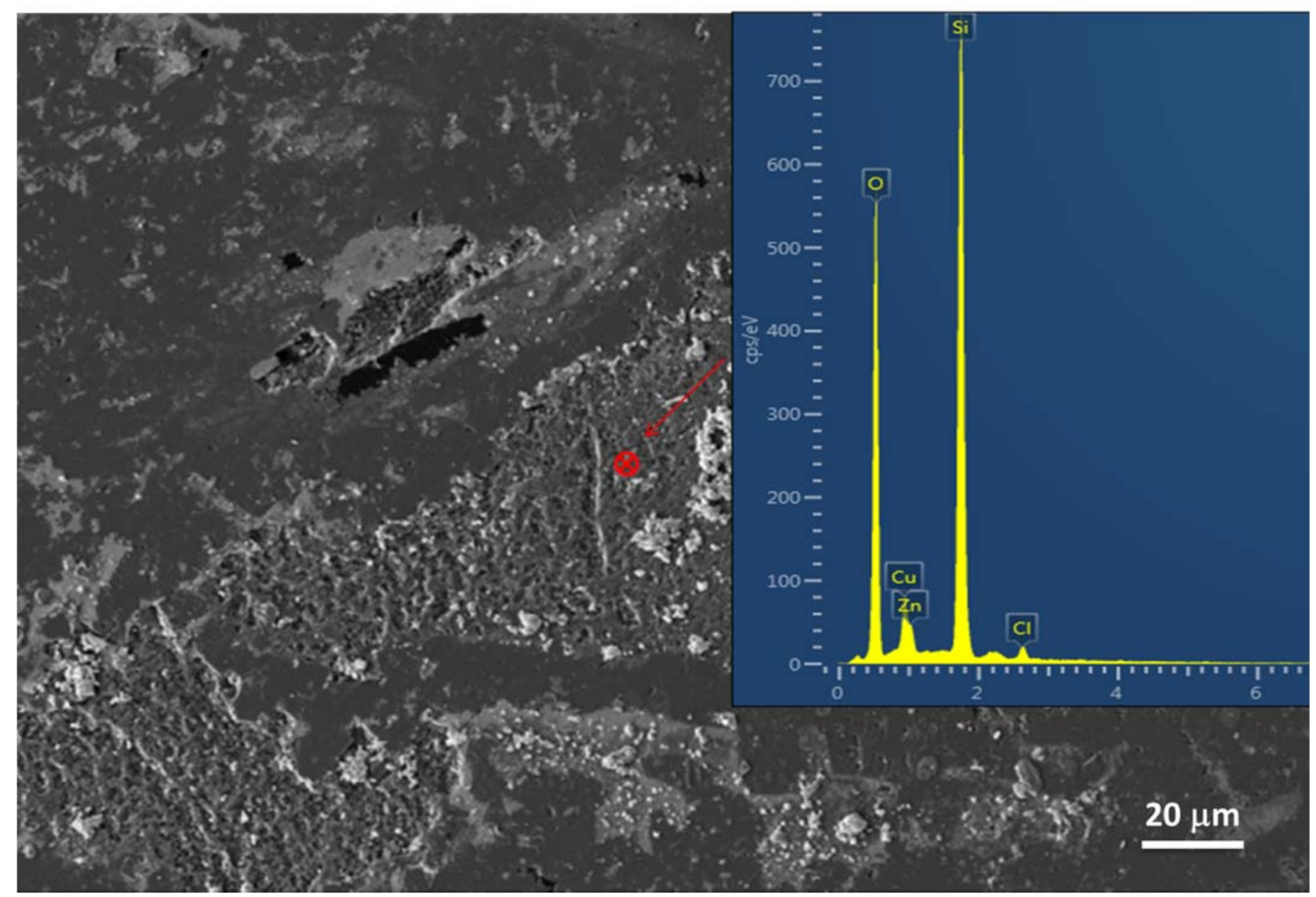

(b)

Figure 13 Representative EDXS spectrum acquired from a SiC and Si region respectively, on a fraction surface of a brake disc in Brake-H after 8 braking stops in water spray environment. 
Table 1 Quantitatively estimated area fraction of main constituents on as-finished friction surfaces of carbon ceramic composite disc.

\begin{tabular}{|c|c|c|c|}
\hline & \multicolumn{3}{|c|}{ Area fraction of key regions in $\mathrm{C}_{\mathrm{f}} / \mathrm{C}-\mathrm{SiC}$ composite (\%) } \\
\hline Brake & $\mathrm{SiC}$ & $\mathrm{Si}$ & $\mathrm{C}_{\mathrm{f}} / \mathrm{C}$ \\
\hline Brake-H & $41.78 \pm 5.8$ & $11.34 \pm 4.8$ & $47.28 \pm 6.4$ \\
\hline Brake-L & $11.6 \pm 6.3$ & $6.1 \pm 4.1$ & $82.3 \pm 10.6$ \\
\hline
\end{tabular}


Table 2

Chemical composition on as-finished surface of a pad, detected with EDXS

\begin{tabular}{|c|c|c|c|c|c|c|c|}
\hline Chemical element & $\mathrm{Fe}$ & $\mathrm{Cu}$ & $\mathrm{C}$ & $\mathrm{O}$ & $\mathrm{Si}$ & $\mathrm{Al}$ & $\mathrm{Mg}$ \\
\hline Weight \% & $33.0 \pm 10.5$ & $22.4 \pm 8.8$ & $11.9 \pm 2.9$ & $15.4 \pm 4.2$ & $1.6 \pm 1.6$ & $2.1 \pm 0.8$ & $2.0 \pm 1.4$ \\
\hline
\end{tabular}


Table 3 Parameters for the parabolic fitting of the CoF curves in bedding stage

\begin{tabular}{|l|l|l|l|l|l|}
\hline parameter & $\mathrm{a}$ & $\mathrm{b}$ & $\mathrm{c}$ & $\mathrm{R}^{2}$ & $\mathrm{CoF}_{\max }$ \\
\hline Brake H & $-6 \times 10^{-6}$ & 0.002 & 0.333 & 0.9522 & 0.50 \\
\hline Brake L & $-5 \times 10^{-5}$ & 0.0023 & 0.293 & 0.9432 & 0.42 \\
\hline
\end{tabular}

